Research Article

\title{
Suppression of Thrust Fluctuation of a New Ironless Tubular Permanent Magnet Synchronous Linear Motor Based on the Halbach Array
}

\author{
Bo Li $\mathbb{D}$, Jun-an Zhang, Zhiping Shi, Xiaolong Zhao, and Hao Dong (iD \\ School of Mechatronic Engineering, Xi'an Technological University, Xi'an 710025, China \\ Correspondence should be addressed to Bo Li; libo_xatu@163.com
}

Received 29 July 2021; Revised 29 October 2021; Accepted 25 November 2021; Published 13 December 2021

Academic Editor: S Bastien Besset

Copyright (c) $2021 \mathrm{Bo} \mathrm{Li} \mathrm{et} \mathrm{al.} \mathrm{This} \mathrm{is} \mathrm{an} \mathrm{open} \mathrm{access} \mathrm{article} \mathrm{distributed} \mathrm{under} \mathrm{the} \mathrm{Creative} \mathrm{Commons} \mathrm{Attribution} \mathrm{License,} \mathrm{which}$ permits unrestricted use, distribution, and reproduction in any medium, provided the original work is properly cited.

\begin{abstract}
The air gap magnetic field (AGMF) is the key factor in determining the ironless tubular permanent magnet synchronous linear motor (ITPMSLM). The distortion of its waveform causes thrust fluctuation during the operation of the motor, resulting in poor machining accuracy of the machine tool. To solve this problem, this paper proposes a new chamfered permanent magnet structure (CPMS) to improve its performance. First, the equivalent magnetic charge method is used to analyze the AGMF, and the analytical expressions of the no-load back EMF and thrust of the new motor are obtained. Second, the AGMF of six kinds of CPMS is analyzed by the Fourier coefficient. Taking the minimum harmonic distortion rate as the optimization objective, the CPMS that makes the AGMF waveform reach the best sinusoidal property is obtained and the no-load back EMF and thrust of the new motor are analyzed. Then, the new motor is compared with the ITPMSLM of rectangle permanent magnet structures (RPMS). Finally, according to the CPMS, the test prototype is built and tested under different working conditions. The research results show that when the outer circumference is $45^{\circ}$ chamfered, the ratio of permanent magnet thickness $h_{2}$ to the chamfered thickness $h_{1}$ is 0.8 ; the sinusoidal property of AGMF is the best, and this structure can effectively reduce the motor thrust fluctuation rates to less than $0.01 \%$, which verifies the effectiveness of the CPMS in improving the sinusoidal property in the AGMF and restraining the thrust fluctuation of the ITPMLSM.
\end{abstract}

\section{Introduction}

The tubular permanent magnet synchronous linear motor (TPMSLM) has the advantages of a simple structure, high utilization rate of the primary winding, no lateral end effect, and easy adjustment and control. It is widely used in highprecision fields such as laser cutting machines [1]. However, with the existence of thrust fluctuation, the motor will produce noise, vibration, and other problems that seriously affect its operating characteristics and reduce machining accuracy $[2,3]$. Therefore, it is of great theoretical and practical significance to carry out research on thrust fluctuation suppression of TPMSLM.

The method of different pole groove matching and the oblique pole are used to weaken the magnetic resistance, which can effectively reduce the thrust fluctuation of the motor [4]. The magnetic resistance of the permanent magnet linear synchronous motor is studied by the numerical calculation method. It is proposed that the thrust fluctuation can be minimized by changing the end tooth structure and magnetic pole shape; the cogging magnetic resistance can also be weakened [5-8]. The relationship between the minimum end force and the primary length is derived; then, the end magnetic resistance is studied by changing the primary length. On the basis of the optimal primary length, the thrust fluctuation is restrained by using the theory of a magnetic separation ring [9]. The integral structure of the auxiliary pole is adopted to weaken the thrust fluctuation. The primary core is connected with the additional auxiliary pole by a magnetic isolation bridge, which can effectively eliminate the source of error and improve the mechanical strength of the motor [10]. A study proposed a double mover 
bilateral Halbach permanent magnet array linear motor that reduces the motor thrust fluctuation by optimizing the motor magnetic pole structure and improving the motor magnetic energy density [11]. Another study proposed a Halbach alternating pole structure by adding two tangential magnetized permanent magnets in the alternating pole structure that can reduce the interpole flux leakage and increase the air gap flux density. This structure helps reduce the thrust fluctuation of motor [12]. The studies used the $\mathrm{v}$-coil and an equivalent magnetization method to analyze the model and a genetic algorithm to locally optimize the motor design and finally obtained a motor model with minimum local thrust fluctuation [13]. Although these studies have effectively weakened the motor thrust fluctuation, the thrust amplitude is also significantly reduced.

Studies used the equivalent magnetization method to solve the electromagnetic field of the motor, which deduces the analytical property of magnetic density, back EMF, and inductance and proposes an improved TPMSLM [14-16]. However, the sinusoidal property of the AGMF in these studies is poor, and the thrust fluctuation is unstudied. A study analyzed TPMSLM with axial and radial magnetization structure by using the method of the equivalent magnetic circuit and equivalent magnetization, respectively; analyzed the influence of several main parameters of the motors on the magnetic field; and obtained the analytical calculation of AGMF intensity and the thrust of TPMSLM. However, this is too complex and inaccurate $[17,18]$. Another study calculated the TPMSLM thrust based on the relationship between the back EMF and thrust, but the calculation of thrust fluctuation suppression was not described [19]. Other studies analyzed the magnetic field of axially magnetized TPMSLM with an analytical method but did not analyze the influence of structural parameters on AGMF, especially thrust fluctuation $[20,21]$. The magnetic pole offset method was used to weaken the cogging force of TPMSLM and give the calculation of the magnetic pole offset, but it is difficult to use this method for the axial magnetization structure of TPMSLM [22, 23]. Although these studies can achieve the purpose of restraining thrust fluctuation, the main disadvantages are that the structural complexity is increased and the manufacturing cost is greatly increased [24, 25]. A TPMSLM with axial magnetization has been designed, and the influence of motor size on performance has been analyzed in detail [26, 27]. Studies conducted an in-depth analysis on the cogging force and eddy current loss of TPMSLM and suppressed the thrust fluctuation through the optimal design of the motor $[28,29]$. A study proposed a primary TPMSLM with flux switching. The motor uses a magnetic isolation bridge to solve the problem of an asymmetric magnetic circuit of end armature winding and suppress thrust fluctuation [30]. However, the primary structure of the motor is complex and difficult to manufacture. Another study proposed a flux reversal primary TPMSLM, which is relatively simple to manufacture, but the motor is a single-phase motor with a large thrust fluctuation and self-starting problems and is not suitable for longdistance drive system applications [31]. In addition, there are usually three common permanent magnet structures in
TPMSLM: a radial magnetization structure, an axial magnetization structure, and a Halbach structure [32]. To enhance the main magnetic field, the stator generally adopts a Halbach array [33].

To sum up, most of the methods to weaken the thrust fluctuation of a TPMSLM are for a TPMSLM with an iron core, and there are few studies on restraining the thrust fluctuation of an ironless tubular permanent magnet synchronous linear motor (ITPMSLM). The AGMF is the key problem in determining the thrust performance of the ITPMSLM, and its waveform distortion is the key factor in producing thrust fluctuation during the operation of an ITPMSLM. Therefore, with a CPMS, the minimum harmonic distortion rate of the AGMF waveform as the optimization objective is proposed to suppress the thrust fluctuation of an ITPMSLM. First, the AGMF distribution, no-load back EMF, and thrust of the motor are calculated based on the equivalent magnetic charge method. Second, the AGMF with six different CPMS kinds is analyzed, and the CPMS that makes the AGMF waveform reach the best sinusoidal property is obtained. The no-load back EMF waveform distortion rate and thrust harmonic content of the new motor are analyzed by an analytical method. Then, the analytical method is verified by a finite element method. Finally, combined with the above scheme, the no-load back EMF and the thrust fluctuation of the new motor are tested to verify the feasibility and effectiveness of the CPMS in improving the sinusoidal property of the AGMF and restraining the thrust fluctuation of the motor.

\section{Topology Design of New ITPMSLM with CPMS of Halbach Array}

The ITPMSLM includes a stator and mover, and its topology is shown in Figure 1. The permanent magnet ring is a Halbach array fixed on the stainless steel back yoke through a special installation process to form the stator, so as to ensure that there will be no relative movement between the stator's permanent magnet ring and the back yoke when the motor works. The winding is encapsulated with special insulating materials such as epoxy resin and forms a mover with the yoke. The winding distribution is as follows: $\mathrm{A}+$, $\mathrm{A}-; \mathrm{B}+, \mathrm{B}-; \mathrm{C}+, \mathrm{C}-$. The mover is lightweight and has a fast speed response, and there is no influence of cogging and end breaking, so there is no cogging effect or end effect. The area formed between the stator and the mover is called the air gap area. To obtain a large thrust and not to affect the movement of the mover, the smaller the air gap area, the better.

Figure 2 shows that after the RPMS of the Halbach array is magnetized, the magnetic lines of the AGMF near the direct contact of the two magnets are distorted greatly and change unevenly, which will increase the thrust fluctuation of the motor. A CPMS is proposed to solve these problems. The permanent magnet is a circular cylinder and chamfered on both sides of the outer circumference. As shown in Figure 3, near the direct contact of the two magnets, the distortion of the magnetic line of force of the AGMF is reduced, and the variation is more uniform through the CPMS, which will reduce the motor's thrust fluctuation. 


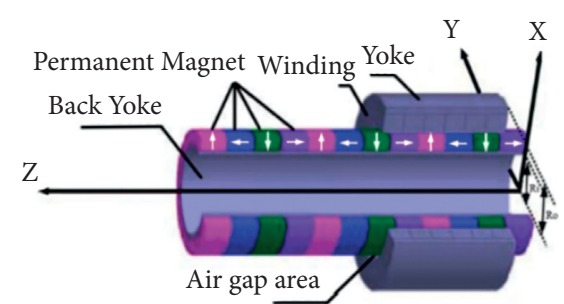

Figure 1: The ITPMSLM topology.

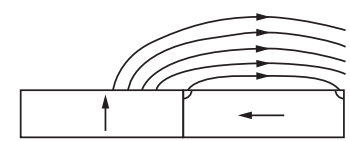

FIgURE 2: The RPMS of the Halbach array.

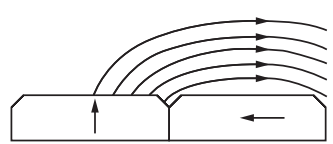

Figure 3: The CPMS of the Halbach array.

\section{Model Establishment of the New Motor}

During the motor operation, the AGMF of the ITPMLSM is a variable vector with size and direction; according to the motor structure, it is divided into the radial component and the axial component, and the AGMF density of the radial component is the main source of motor thrust. Therefore, this section first calculates the analytical model of radial AGMF density [34] and then calculates the analytical model of the no-load back EMF and thrust of the ITPMSLM with CPMS of the Halbach array (hereinafter referred to as the new motor).

\subsection{Building the Analytical Model for the AGMF. The CPMS} constituting the stator of the new motor in Figure 1 is completely symmetrically distributed along the central axis in space, and the magnetic charges density on the upper, lower, left, and right surfaces is $M$. Now, take the CPMS magnetized along the $+x$ direction as an example, and the magnetic field analytical model is as shown in Figure 4.

Before building the analytical model of AGMF, make the following assumptions:

(1) The length of the motor stator is infinite

(2) The permeability of the motor back yoke is infinite

(3) The permanent magnet is uniformly magnetized without demagnetization

The magnetic field is a static magnetic field, and the magnetic charge equation can be obtained by

$$
\left\{\begin{array}{l}
\nabla \cdot B=0 \\
\nabla \times H=0 \\
B=\mu_{0}(H+M) \\
H=-\nabla \varphi_{m 1} \\
\nabla^{2} \varphi_{m 1}=\nabla \cdot M
\end{array}\right.
$$

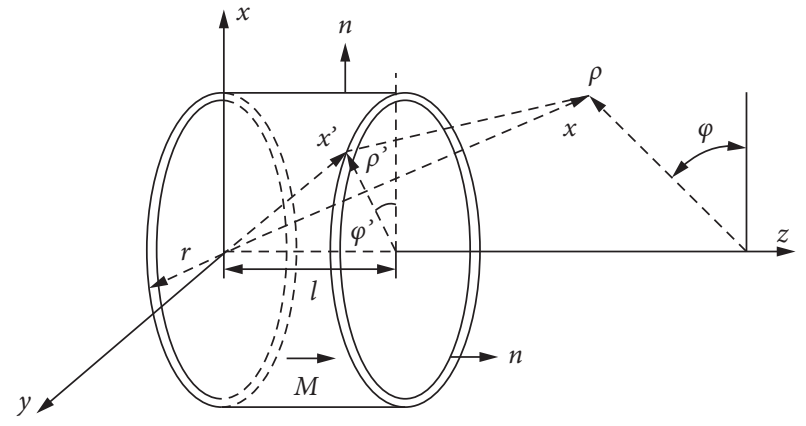

Figure 4: New motor model in $+x$ direction.

where $M$ is the surface magnetic charge density of permanent magnet, unit: $\mathrm{A} / \mathrm{m}^{2}$. Moreover, the scalar $\phi_{m 1}$ can be obtained from (1):

$$
\phi_{m 1}=\frac{M}{4 \pi} \int_{0}^{r} \int_{0}^{2 \pi} \frac{\rho^{\prime} \mathrm{d} \rho / \mathrm{d} \phi^{\prime}}{\left|x-x^{\prime}\right|^{3}} .
$$

In Figure 4, $r$ is the radius of the permanent magnet; $\rho^{\prime}$ and $\varphi^{\prime}$ are the coordinates of the magnetic charge point in the source area; $\rho$ and $\varphi$ are the coordinates of the field point; the position vector of the field point is $x$; and $x^{\prime}$ is the position vector of the source point. For $\left|x-x^{\prime}\right|^{-1}$, use the integral transformation in [26] and the properties of the Bessel function of imaginary argument [27] to calculate the gradient of the $\phi_{m 1}$, and the radial flux density of $+x$ magnetization can be obtained as follows:

$$
\begin{aligned}
B_{x 1+}= & B_{\rho 1}+B_{\rho 2}=\frac{\mu_{0} M}{\pi} \int_{0}^{\infty} \mathrm{d} k \cos [k(z-l)] K_{1}(k \rho) r I_{1}(k r) \\
& +\frac{\mu_{0} M}{\pi} \int_{0}^{\infty} \mathrm{d} k \cos (k z) K_{1}(k \rho) r I_{1}(k r) .
\end{aligned}
$$

Similarly, the radial flux densities of the three sides magnetized in the $-x,+y$, and $-y$ directions can be calculated as follows:

$$
\begin{aligned}
B_{x 1-}= & B_{\rho 3}+B_{\rho 4}=-\frac{\mu_{0} M}{\pi} \int_{0}^{\infty} \mathrm{d} k \sin [k(z-l)] K_{1}(k \rho) r I_{1}(k r) \\
& -\frac{\mu_{0} M}{\pi} \int_{0}^{\infty} \mathrm{d} k \sin (k z) K_{1}(k \rho) r I_{1}(k r), \\
B_{y 1+}= & B_{\rho 5}+B_{\rho 6}=\frac{\mu_{0} M}{\pi} \int_{-r}^{+r} \mathrm{~d} k \cos [k(x-r)] K_{1}(k \rho) r I_{1}(k r) \\
& +\frac{\mu_{0} M}{\pi} \int_{-r}^{+r} \mathrm{~d} k \cos [k(x+r)] K_{1}(k \rho) r I_{1}(k r), \\
B_{y 1-}= & B_{\rho 5}+B_{\rho 6}=-\frac{\mu_{0} M}{\pi} \int_{-r}^{+r} \mathrm{~d} k \sin [k(x-r)] K_{1}(k \rho) r I_{1}(k r) \\
& -\frac{\mu_{0} M}{\pi} \int_{-r}^{+r} \mathrm{~d} k \sin [k(x+r)] K_{1}(k \rho) r I_{1}(k r) .
\end{aligned}
$$

Because the motor stator is composed of $n$ permanent magnets, using the superposition principle, the magnetic density of the AGMF of the motor can be obtained as follows: 


$$
B(\rho, z)=\sum_{n=1}^{\infty}\left(B_{x n+}+B_{x n-}+B_{y n+}+B_{y n+}\right) .
$$

\subsection{Building the Analytical Model for No-Load Back EMF and} Thrust. The winding coil of the new motor is surrounding the stator in an axisymmetric manner, and each phase winding is formed by several groups of coils in series. Figure 5 is a schematic diagram of the winding, where $R_{S}$ is the outer radius of the winding, $R_{S 1}$ is the inner radius of the winding, $t_{w}$ is the axial width of the winding, and $h_{w}$ represents the thickness of the winding.

According to Faraday's law of electromagnetic induction, when the mover moves in a straight line along the $Z$ axis, the radial magnetic field will be cut in each ring coil to produce a no-load back EMF. The no-load back EMF generated in each coil is derived according to (5), and then the no-load back EMF of the same phase coil can be added to obtain the noload total back EMF. However, the calculation process is complex and time-consuming. To simplify the calculation, it can be assumed that all coils are concentrated at the average radius. As shown in Figure 5, if the position of the axis of a group of coils is $Z$, the average magnetic density of the radial AGMF in the coil area of the group is the following:

$$
B_{\mathrm{av}}(z)=\frac{1}{\left(R_{s}-R_{s 1}\right) t_{w}} \int_{z-t_{w} / 2}^{z+t_{w} / 2} \int_{R_{s 1}}^{R_{s}} B(\rho, z) \rho \mathrm{d} \rho \mathrm{d} z .
$$

The no-load back EMF of this group of coils at this position is the following:

$$
E_{A}=N B_{\mathrm{av}} L_{\mathrm{av}} v=\pi N B_{\mathrm{av}}(z)\left(R_{\mathrm{s}}+R_{s 1}\right) v .
$$

In (7), $N$ is the number of winding turns and $L_{\mathrm{av}}$ is the average length of coil per turn. Using the above assumptions, it is considered that the coils are concentrated at the average magnetic density, and the thrust of a group of coils can be obtained as follows:

$$
F(z)=N B_{\mathrm{av}} L_{\mathrm{av}} I=\pi N B_{\mathrm{av}}(z)\left(R_{s}+R_{\mathrm{s} 1}\right) I(z) .
$$

$I_{(z)}$ is the alternating current input to the winding. The total motor thrust can be obtained by adding the thrust to all coil groups. The thrust fluctuation rate is taken as the thrust fluctuation analysis index and is defined as

$$
F_{w}=\frac{F_{\text {max }}-F_{\text {min }}}{F_{\text {avg }}},
$$

where $F_{\max }$ is the maximum thrust value in the stroke, $F_{\min }$ is the minimum thrust value in the stroke, and $F_{\text {avg }}$ is the average thrust in the stroke.

The thrust fluctuation rate can reflect the stability of thrust during motor operation. The smaller the thrust fluctuation rate, the more stable the motor operation (i.e., the smaller the thrust fluctuation).

\section{Model Calculation and Analysis of the New Motor}

4.1. Analysis of AGMF. Because the sinusoidal waveform of radial $A G M F$ is the key problem of motor thrust fluctuation,

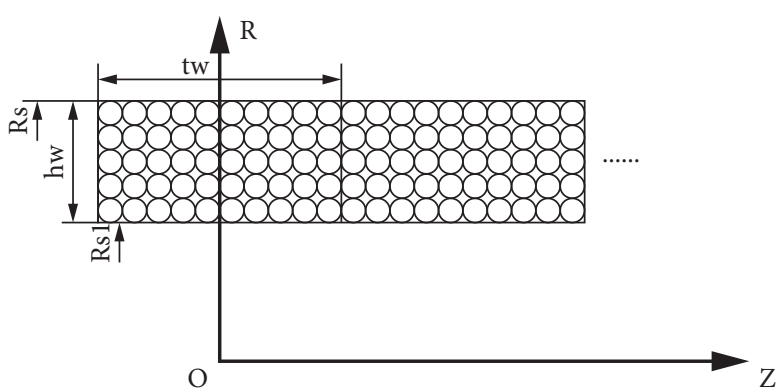

FIGURE 5: Schematic diagram of the winding.

the analytical model of AGMF of the different CPMS will be analyzed in this section, and the optimal sinusoidal radial AGMF waveform will be determined in combination with the total harmonic distortion rate of the radial AGMF waveform.

The new motor design is symmetrical along the central axis, so it can take the half-plane simplified into a two-dimensional plane for research, as shown in the physical model of CPMS in Figure 6.

The chamfer here is $45^{\circ}$ chamfer along the outer circumference. When the polar distance and thickness $h_{2}$ of the CPMS are determined, the different chamfered thickness $h_{1}$ is selected to calculate the radial AGMF at different $h_{1} / h_{2}$. Take the magnetic induction intensity of radial AGMF at $r=15 \mathrm{~mm}$ for analysis, and the results are shown in Figure 7.

Fourier analysis of the radial AGMF at different $h_{1} / h_{2}$ in Figure 7 will obtain the fundamental wave and harmonic content, as shown in Figure 8.

To unify the standard to measure the sinusoidal nature of the waveform, the total harmonic distortion rate (THD) of radial AGMF is defined as its evaluation index. The THD is

$$
B_{\mathrm{THD}}=\sum \frac{B_{y v}}{B_{y 1}}
$$

It can be seen from Figure 8 that as $h_{1} / h_{2}$ becomes smaller, the fundamental amplitude of the radial AGMF also gradually decreases. The higher the $h_{1} / h_{2}$ is, the larger the chamfer and the smaller the radial AGMF induction intensity are. To compare the performance of CPMS at different $h_{1} / h_{2}$, the total harmonic distortion rate of radial AGMF under corresponding conditions is calculated, as shown in Table 1.

Table 1 shows that the smaller the THD, the smaller the harmonic components of the reflected waveform and the better the sine of the waveform. Through the comparative analysis of magnetic density harmonics and distortion rate of radial AGMF under six structures when $h_{1} / h_{2}=0.8$, the amplitude of radial AGMF density waveform is relatively high and the waveform distortion rate is low. Therefore, the CPMS in this paper can effectively improve the sinusoidal characteristic of the radial AGMF waveform and achieve the best result.

4.2. Analysis of No-Load Back EMF. According to the above analysis, the sinusoidal waveform of the radial AGMF is best when $h_{1} / h_{2}=0.8$. Based on this, the no-load back EMF 


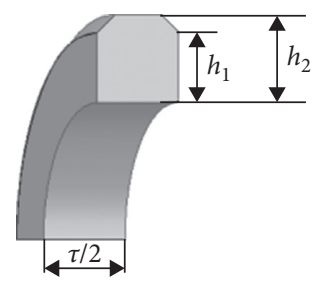

Figure 6: Physical model of CPMS.

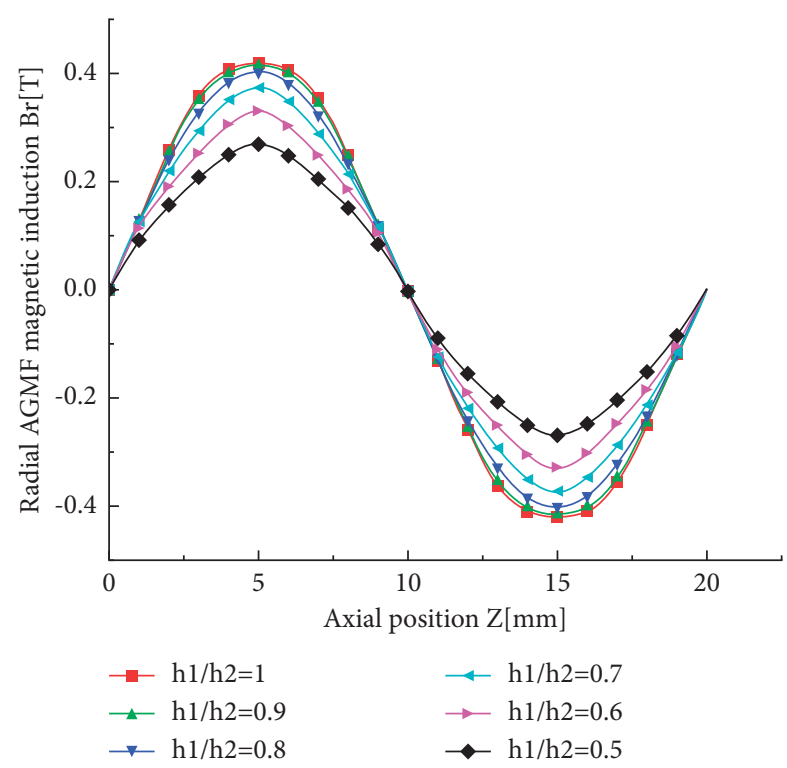

FIGURE 7: Magnetic induction intensity of radial AGMF at different $h_{1} / h_{2}$.

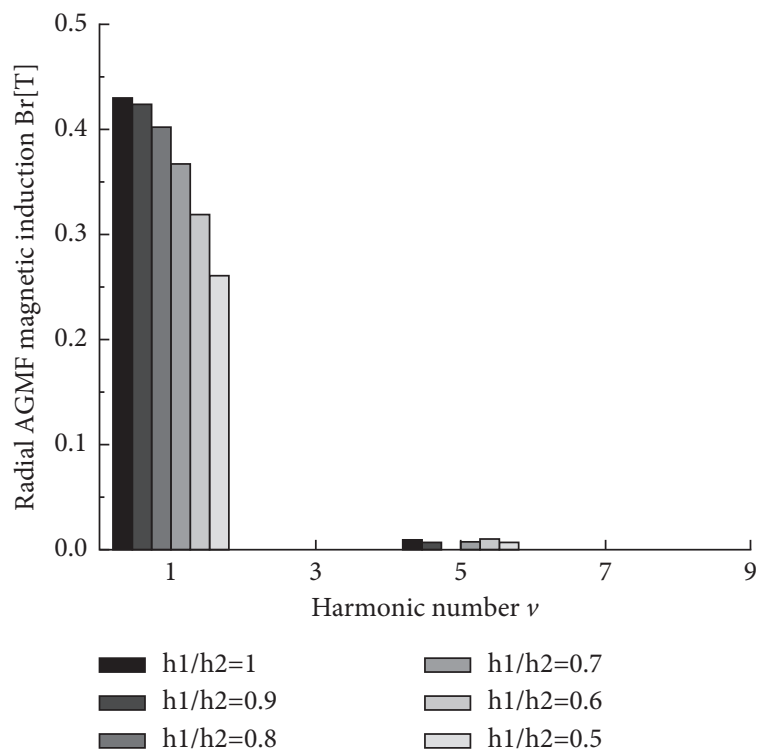

FIGURE 8: Harmonic analysis of magnetic induction intensity in radial AGMF at different $h_{1} / h_{2}$.

analytical model of the new motor is established. The noload back EMF waveforms in the three-phase winding when the mover moves axially at $v=0.02 \mathrm{~m} / \mathrm{s}$ and $v=1 \mathrm{~m} / \mathrm{s}$ are calculated using (7), and the three-phase no-load back EMF waveform and harmonic content obtained by the analytical model are analyzed (see Figures 9 and 10).

By building the no-load back EMF model of the new motor, the no-load back EMF of the motor when $v=0.02 \mathrm{~m} /$ $s$ and $v=1 \mathrm{~m} / \mathrm{s}$ are calculated, and results of the numerical method are compared with those of the analytical method (see Figures 9 and 10).

Figures 9 and 10 show that when the new motor operates at $v=0.02 \mathrm{~m} / \mathrm{s}$ and $v=1 \mathrm{~m} / \mathrm{s}$, the no-load back EMF has a good sinusoidal performance, and only a few fifth harmonics exist in each harmonic component of the no-load back EMF, which shows that the no-load back EMF harmonic of the new motor can be effectively suppressed by using the CPMS on the premise of ensuring the sinusoidal waveform of the radial AGMF. It provides a strong basis for the subsequent analysis of the thrust and thrust fluctuation analytical model.

4.3. Analysis of Thrust. The AGMF is the key problem of the motor thrust. Equation (8) is derived from (6) assuming that the winding radii of all coils are concentrated at the average radius. Therefore, to verify the effectiveness and correctness of the CPMS, this paper establishes the thrust analytical model of the new motor when $I(z)=1.3 \mathrm{~A}$ (see Table 3 for the new motor parameters); the thrust waveform and harmonic content of the new motor are obtained by the analytical model as shown in Figure 11.

Figure 11 shows that the thrust of the new motor is sinusoidal, but there are still harmonics that cause thrust fluctuation. To determine the harmonic times and content, we calculate the harmonic components in thrust through Fourier analysis (see Table 2).

Table 2 shows that, in addition to the DC component, there are multiple harmonic components of the sixth in the thrust, and the harmonic content of other times is almost zero. Therefore, the motor thrust can be expressed as the sum of the DC component and multiple harmonic components of 6 th; that is,

$$
\begin{aligned}
F(z)= & 15.1735+0.1832 \times \sin (6 \times 2 \pi f \times t) \\
& +0.0165 \times \sin (12 \times 2 \pi f \times t) \\
& +0.0083 \times \sin (18 \times 2 \pi f \times t)+\cdots .
\end{aligned}
$$

Equation (11) can be further simplified. In the multiple harmonic components of the sixth, except for the sixth harmonic, the sum of other harmonic contents is less than $0.1 \%$ of the total thrust, which can be simplified as

$$
F(z)=15.1735+0.1832 \times \sin (6 \times 2 \pi f \times t) .
$$

Thus, the sum of each harmonic of the thrust of the new motor accounts for $0.67 \%$ of the total thrust of the motor, and the distortion rate of the thrust waveform is less than $0.01 \%$. The analytical results of the thrust show that the CPMS can effectively suppress the thrust fluctuation caused by the distortion of the radial AGMF waveform of the ITPMSLM and stabilize the thrust output of the motor. 
TABLE 1: Relationship between $h_{1} / h_{2}$ and fundamental wave and harmonic of radial AGMF.

\begin{tabular}{|c|c|c|c|c|c|c|}
\hline \multirow{2}{*}{$h_{1} / h_{2}$} & \multirow{2}{*}{ Fundamental wave $(\mathrm{T})$} & \multicolumn{4}{|c|}{ Harmonic $(\mathrm{T})$} & \multirow{2}{*}{ THD (\%) } \\
\hline & & 3 & 5 & 7 & 9 & \\
\hline 1.0 (RPMS) & 0.4304 & 0.0011 & 0.0091 & 0 & 0.0004 & 2.46 \\
\hline 0.9 & 0.4231 & 0.0009 & 0.0064 & 0 & 0 & 1.73 \\
\hline 0.8 & 0.4020 & 0.0007 & 0.0002 & 0 & 0.0004 & 0.32 \\
\hline 0.7 & 0.3673 & 0.0004 & 0.0066 & 0 & 0.0002 & 1.96 \\
\hline 0.6 & 0.3202 & 0.0001 & 0.0092 & 0 & 0.0003 & 3.00 \\
\hline 0.5 & 0.2622 & 0 & 0.0064 & 0 & 0.0003 & 2.56 \\
\hline
\end{tabular}

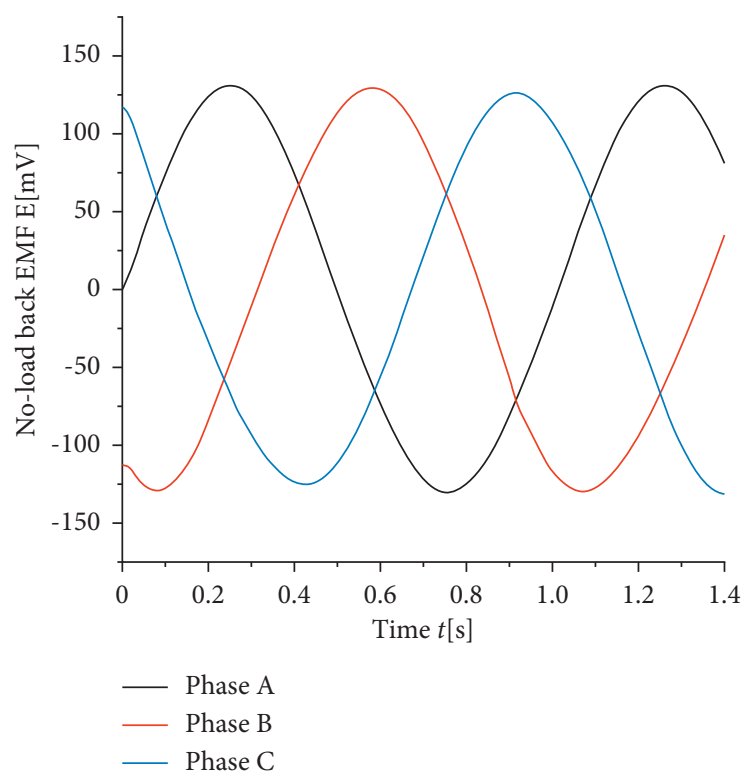

(a)

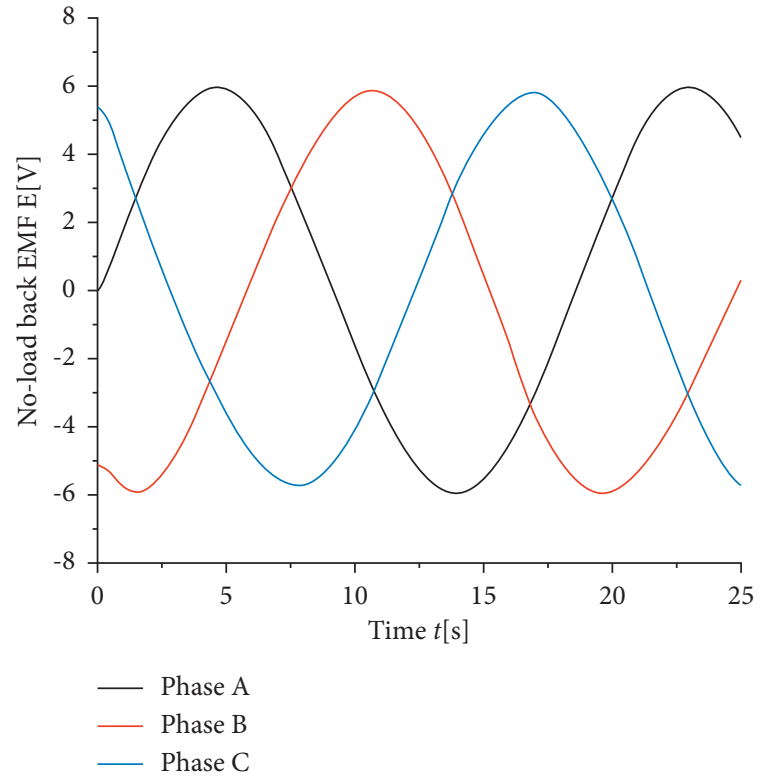

(b)

FIGURE 9: Waveform diagram of no-load back EMF of the new motor at different speeds: (a) $v=0.02 \mathrm{~m} / \mathrm{s}$; (b) $v=1 \mathrm{~m} / \mathrm{s}$.

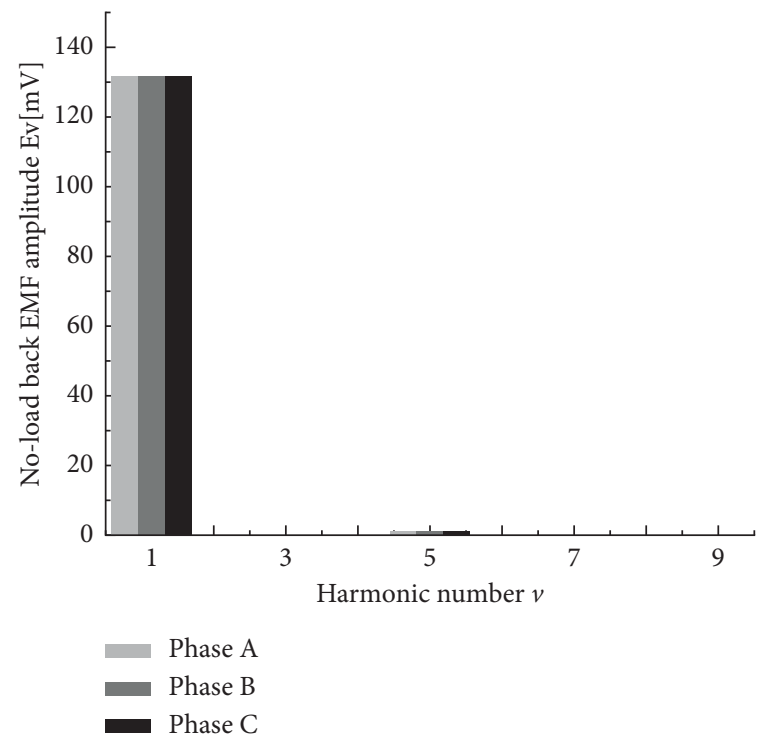

(a)

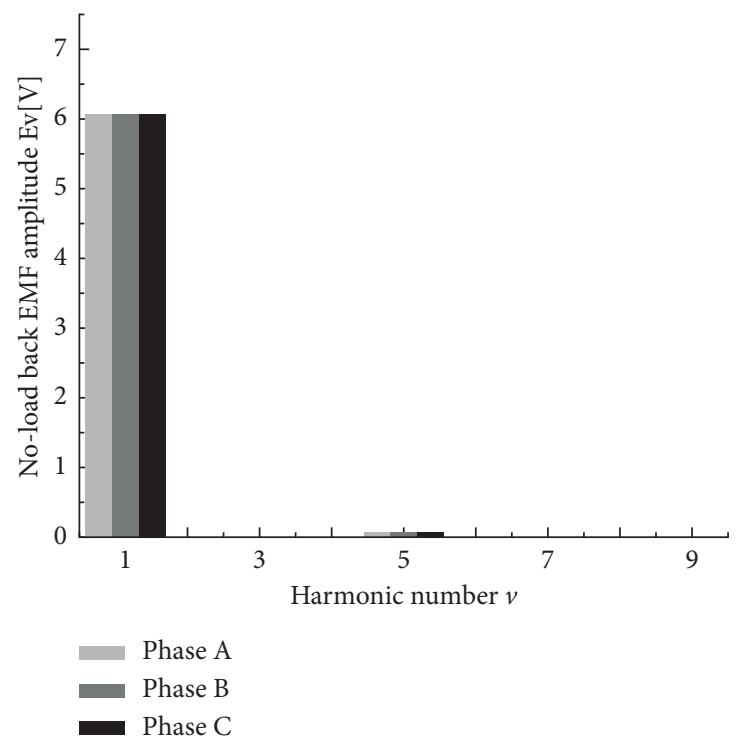

(b)

FIgURe 10: Harmonic analysis of no-load back EMF of the new motor at different speeds: (a) $v=0.02 \mathrm{~m} / \mathrm{s}$; (b) $v=1 \mathrm{~m} / \mathrm{s}$. 


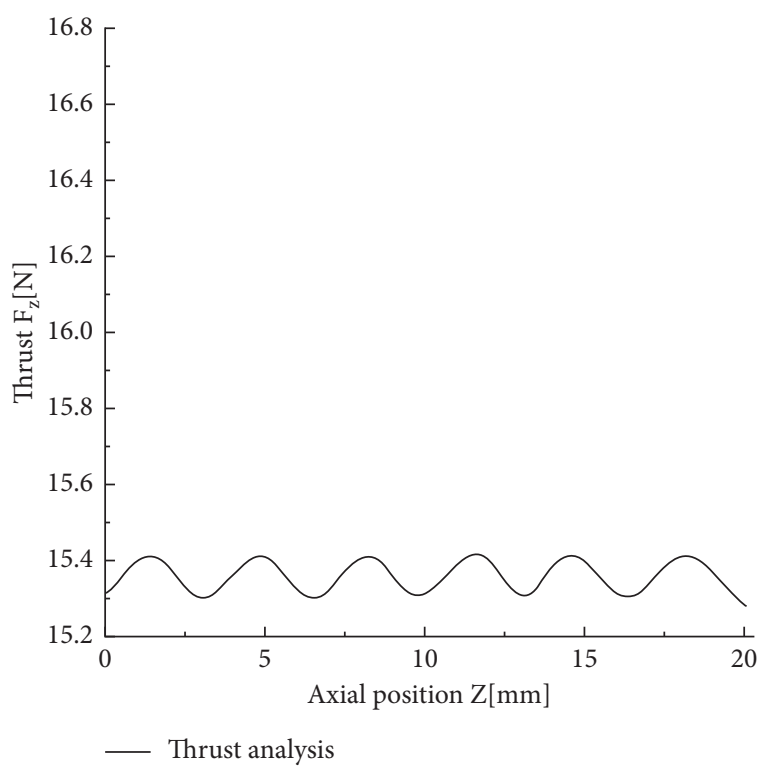

(a)

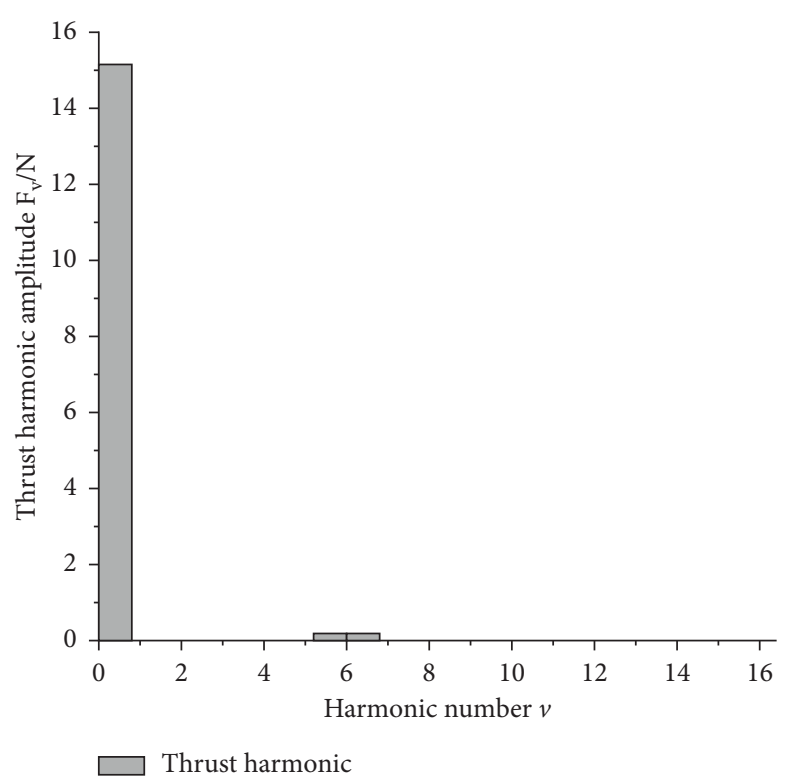

(b)

FIGURE 11: Comparison of motor thrust: (a) motor thrust analysis diagram; (b) motor thrust harmonic analysis diagram.

TABLE 2: Thrust harmonic content of the new motor.

\begin{tabular}{lcc}
\hline Harmonic number $v$ & Thrust $F_{z}(\mathrm{~N})$ & $\begin{array}{c}\text { Harmonic distortion } \\
\text { thrust rate }(\%)\end{array}$ \\
\hline 0 & 15.1735 & \\
2 & 0.0009 & 0.0059 \\
4 & 0.0017 & 0.0112 \\
6 & 0.0832 & 0.1074 \\
8 & 0.0006 & 0.0040 \\
10 & 0.0011 & 0.0072 \\
12 & 0.0065 & 0.0087 \\
14 & 0.0013 & 0.0086 \\
16 & 0.0002 & 0.0013 \\
18 & 0.0083 & 0.0547 \\
\hline
\end{tabular}

\section{Finite Element Verification}

5.1. Finite Element Verification of AGMF. The above analytical model of the new motor is analyzed. To further verify the correctness of the CPMS in reducing the distortion rate of the AGMF waveform and restraining thrust fluctuation, this section makes a finite element comparative analysis between the new motor and the ITPMSLM with the RPMS of the Halbach array. It should be noted that except for the different shapes of permanent magnets (the pole distance and thickness of permanent magnets are the same), the motor structure parameters of the ITPMSLM with RPMS of the Halbach array are consistent with those of the new motor (see Table 3).

Figures 12 and 13 show the finite element analysis cloud diagrams of magnetic flux density of the magnetized magnetic field of the ITPMSLM of the CPMS and RPMS of the Halbach array.

Figures 14 and 15 are the magnetic line finite element analysis cloud diagrams of the magnetizing magnetic field of the ITPMSLM with the CPMS and RPMS of the Halbach array.
TABLE 3: Optimized structural parameters of the new motor.

\begin{tabular}{lc}
\hline Parameter & Value \\
\hline Permanent magnet material & $\mathrm{N} 42$ \\
Remanence density $B_{r}(\mathrm{~T})$ & 1.3 \\
Inner radius of permanent magnet $R_{0}(\mathrm{~mm})$ & 8 \\
Outer radius of permanent magnet $R_{m}(\mathrm{~mm})$ & 13 \\
Chamfer thickness $h_{1}(\mathrm{~mm})$ & 4 \\
Length of axial magnetized permanent magnet $\tau_{m z}(\mathrm{~mm})$ & 5 \\
Length of radial magnetized permanent magnet $\tau_{m r}(\mathrm{~mm})$ & 5 \\
Polar distance $\tau(\mathrm{mm})$ & 10 \\
Inner radius of winding $R_{s 1}(\mathrm{~mm})$ & 14 \\
Outer radius of winding $R_{s}(\mathrm{~mm})$ & 20.5 \\
Winding axial width $t_{w}(\mathrm{~mm})$ & 6.5 \\
Winding thickness $h_{w}(\mathrm{~mm})$ & 6.5 \\
Air gap $g(\mathrm{~mm})$ & 1 \\
Winding turns $N_{c}$ & 144 \\
\hline
\end{tabular}

According to the finite element analysis of Figures 12 and 13 , the magnetic flux density of the RPMS excitation magnetic field at the interface of the permanent magnet is enhanced, resulting in the large distortion of the magnetic line in the process of forming the loop (as shown in Figure 15), resulting in poor sinusoidal characteristics of the radial AGMF. However, the flux density of the CPMS at the interface of the permanent magnet is evenly distributed, and the closed-loop distortion of the magnetic line is very small (as shown in Figure 14), which makes the radial AGMF sinusoidal.

According to the above analysis, the magnetic density of the radial AGMF center of the excitation magnetic field composed of two magnetic pole structures at $r=15 \mathrm{~mm}$ is selected for the finite element comparative analysis. The calculation results are shown in Figure 16.

Figure 16 shows that the finite element result of the radial AGMF center magnetic induction intensity of the RPMS has an error of $3.2 \%$ in the distribution of the standard 


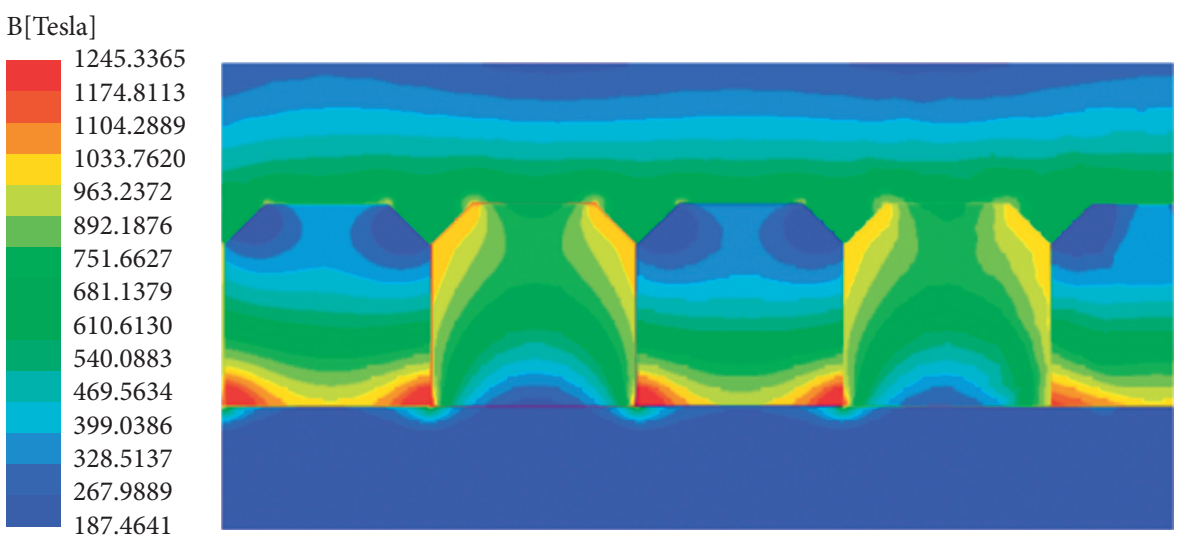

FIgURE 12: Cloud diagram of finite element of magnetic flux density of the CPMS.

$\mathrm{B}[$ Tesla $]$
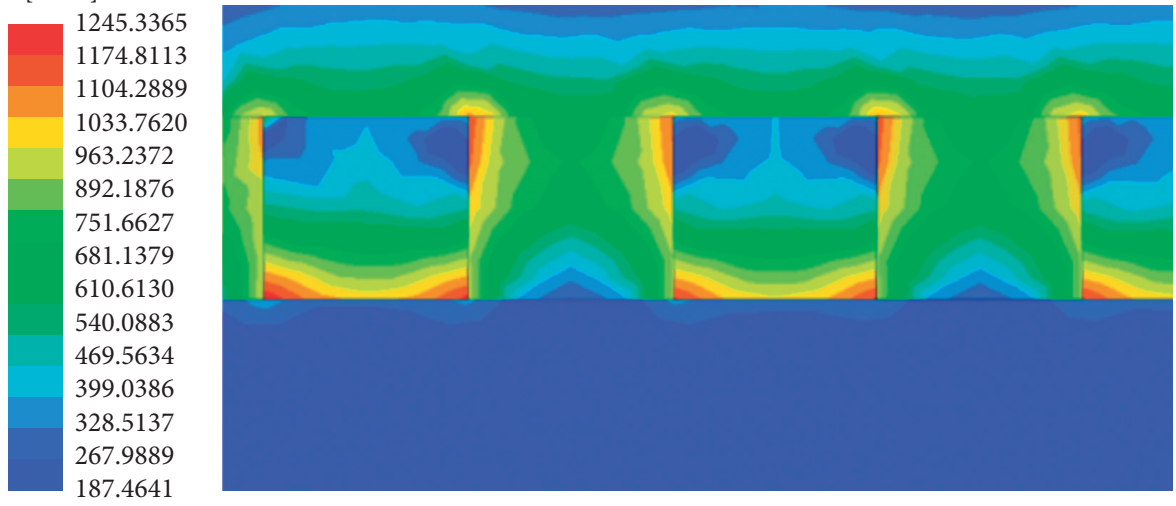

FIGURE 13: Cloud diagram of finite element of magnetic flux density of the RPMS.
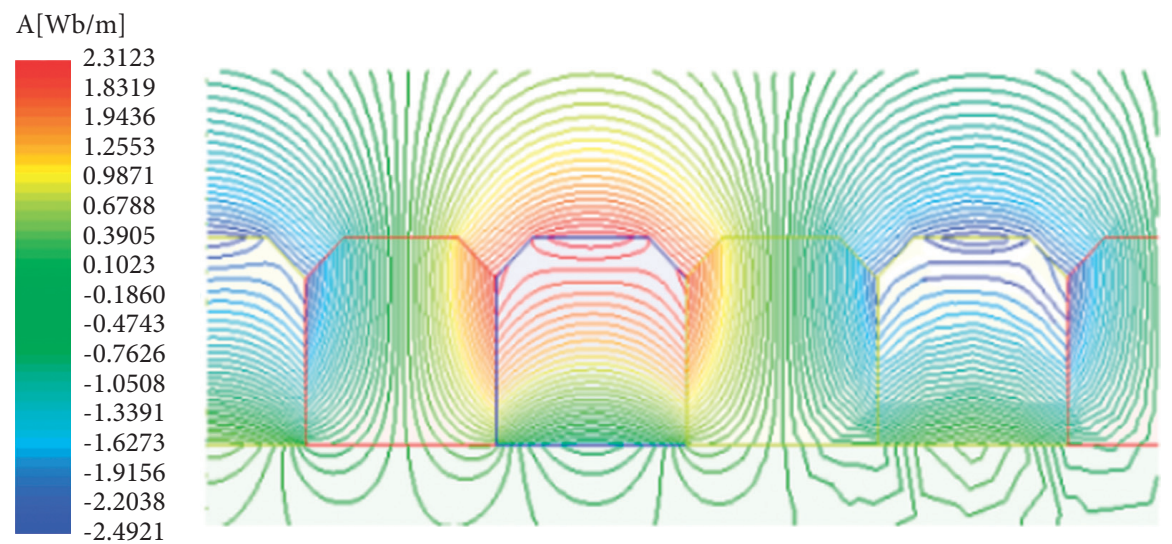

FIGURE 14: Cloud diagram of finite element analysis of magnetic line of the CPMS.

sinusoidal function 1 , whereas the finite element result of the radial AGMF center magnetic density of the CPMS basically fits with the standard sinusoidal function 2 . The results show the radial AGMF magnetic field produced by the CPMS has better sinusoidal and harmonic content and is less than that of the RPMS.
5.2. Finite Element Verification of No-Load Back EMF. The distortion of the AGMF waveform has a great influence on the waveform of no-load back EMF. Therefore, in this paper, the no-load back EMF generated in the three-phase winding when the mover of the ITPMSLM with CPMS of the Halbach array of the CPMS and the RPMS moves at 


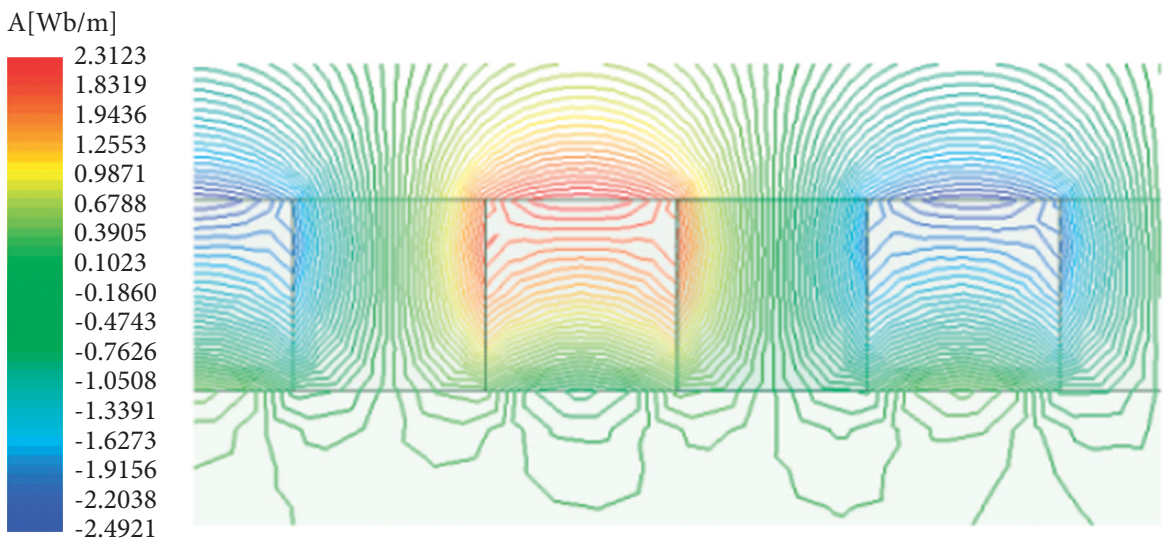

FIGURE 15: Cloud diagram of finite element analysis of magnetic line of the RPMS.

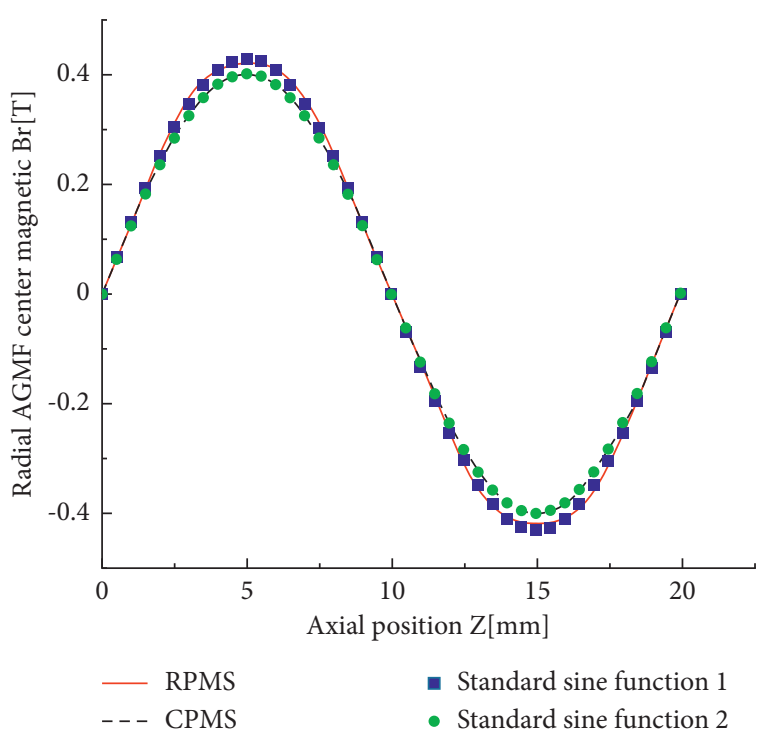

FIgURE 16: Radial AGMF magnetic induction intensity of CPMS and RPMS.

$v=0.02 \mathrm{~m} / \mathrm{s}$ and $v=1 \mathrm{~m} / \mathrm{s}$ is analyzed by the finite element method. The analysis results are shown in Figure 17.

Because of the symmetrical structure of the motor, there are no even harmonics in the no-load back EMF. Take the phase A no-load back EMF waveform in Figure 17 for Fourier analysis and obtain the fundamental wave, higher harmonic content, and total harmonic distortion rate of phase A no-load back EMF of the two magnetic pole structures (see Table 4).

Table 4 shows that by comparing the no-load back EMF of the two motors through the finite element method, the harmonic distortion rates at $v=0.02 \mathrm{~m} / \mathrm{s}$ and $v=1 \mathrm{~m} / \mathrm{s}$ are $0.43 \%, 0.33 \%, 0.23 \%$, and $0.21 \%$, respectively. That is, the total harmonic distortion rate of the no-load back EMF of the new motor is lower, and it is verified that the CPMS can improve the sinusoidal nature of the radial AGMF.

5.3. Finite Element Verification of Thrust. To verify the effectiveness of the CPMS in restraining the thrust fluctuation of the ITPMSLM, the thrust models of the CPMS and RPMS are compared by the finite element method, and the thrust distribution curves under the two permanent magnet structures are obtained, as shown in Figure 18.

According to the above finite element results and in combination with (9), the thrust fluctuation rates of the ITPMSLM with CPMS and RPMS of the Halbach array are 0.01191 and 0.00694 , respectively. The results show that the thrust fluctuation of the ITPMSLM is effectively reduced on the premise of ensuring the best sinusoidal waveform of AGMF and a minimal distortion rate.

Figure 18 shows that the air AGMF magnetic density is optimized by taking the angle cutting in the CPMS as a variable. As a result, the thrust fluctuation decreased significantly (by 41.7\%), but the average thrust also decreased slightly (by $6.49 \%$ ). The conclusion is that the application of the optimized structure proposed in this paper should not only greatly reduce the thrust fluctuation but also may address not significantly reducing the average thrust of motor.

\section{Thrust Performance Test}

6.1. New Motor Experiment Platform. To further verify the effectiveness of this method, the new motor is made, and the dynamic test experiment of thrust fluctuation is carried out. The thrust fluctuation test principle is that in the process of the thrust fluctuation test, the stator, support frame, and pulley of the tested new motor are fixed on the granite platform, and the mover and moving guide rail of the new motor are integrally connected so as to realize high straightness of movement along the static guide rail as the support guide and connect the moving guide rail with the load through the force sensor. The driver gives the motor a one-way movement command (i.e., pulling the load movement). The new motor will pull down the load to make a linear motion under the action of the electromagnetic thrust, and the thrust can be read through the force sensor. Therefore, the thrust fluctuation of the motor can be obtained by analyzing the data read by the force sensor. According to the measurement principle of motor thrust fluctuation, the thrust fluctuation test scheme shown in Figure 19 can be obtained. 


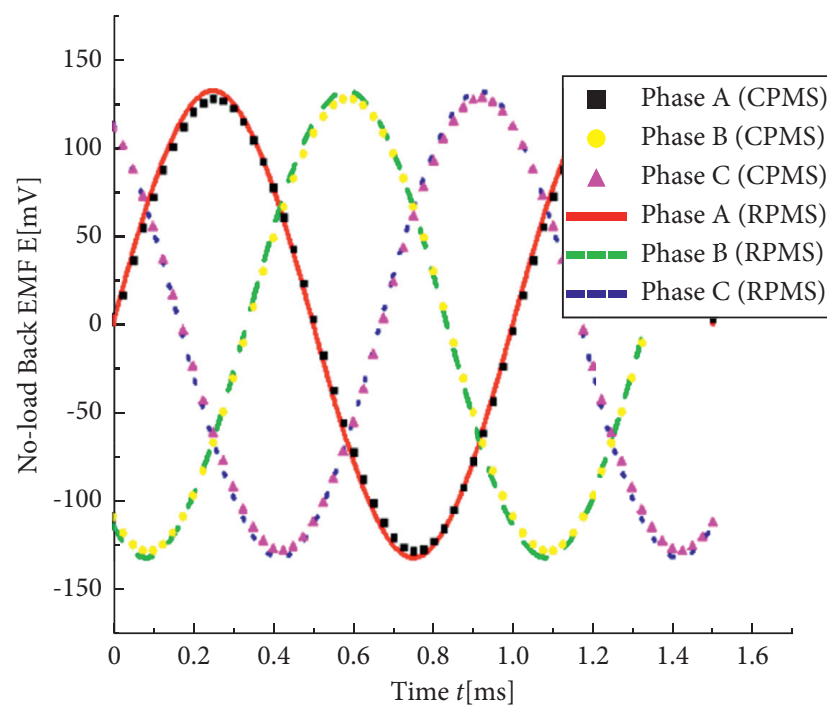

(a)

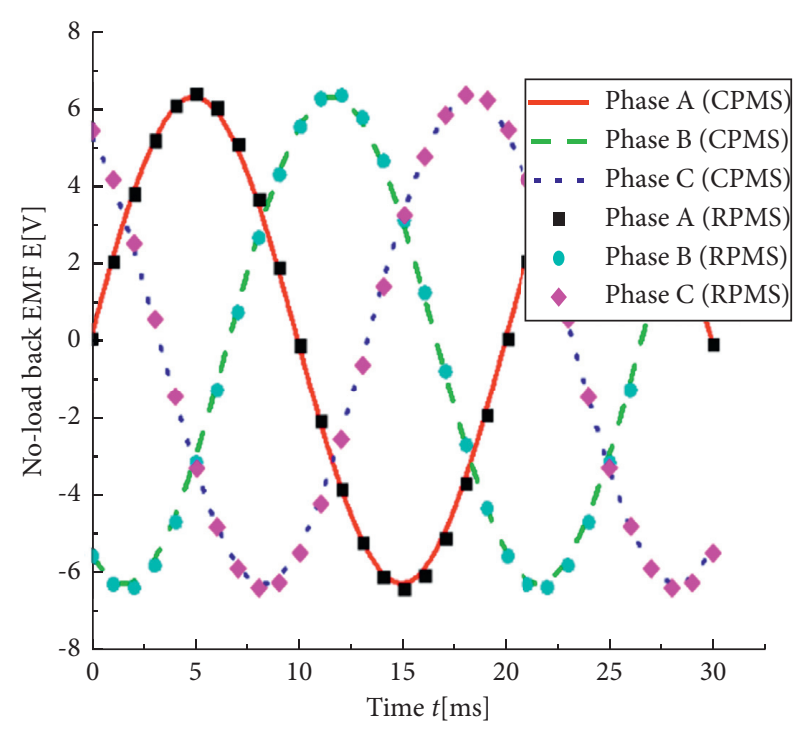

(b)

Figure 17: No-load back EMF distribution of CPMS and RPMS: (a) $v=0.02 \mathrm{~m} / \mathrm{s}$; (b) $v=1 \mathrm{~m} / \mathrm{s}$.

TABLE 4: Total harmonic distortion rate of no-load back EMF of CPMS and RPMS.

\begin{tabular}{lccccc}
\hline \multirow{2}{*}{ Type } & \multicolumn{3}{c}{ Harmonic number $v$} & \multicolumn{2}{c}{ THD\% } \\
& \multirow{2}{*}{ Fundamental wave $(\mathrm{V})$} & 3 & 5 & 7 & 0.0001 \\
RPMS $(v=0.02 \mathrm{~m} / \mathrm{s})$ & 0.1366 & 0.0002 & 0.0003 & 0 & 0.43 \\
CPMS $(v=0.02 \mathrm{~m} / \mathrm{s})$ & 0.1257 & 0.0001 & 0.0002 & 0 & 0.23 \\
RPMS $(v=1 \mathrm{~m} / \mathrm{s})$ & 6.5898 & 0.0002 & 0.0214 & 0 & 0.0003 \\
CPMS $(v=1 \mathrm{~m} / \mathrm{s})$ & 6.3569 & 0.0001 & 0.0135 & 0 & 0 \\
\hline
\end{tabular}

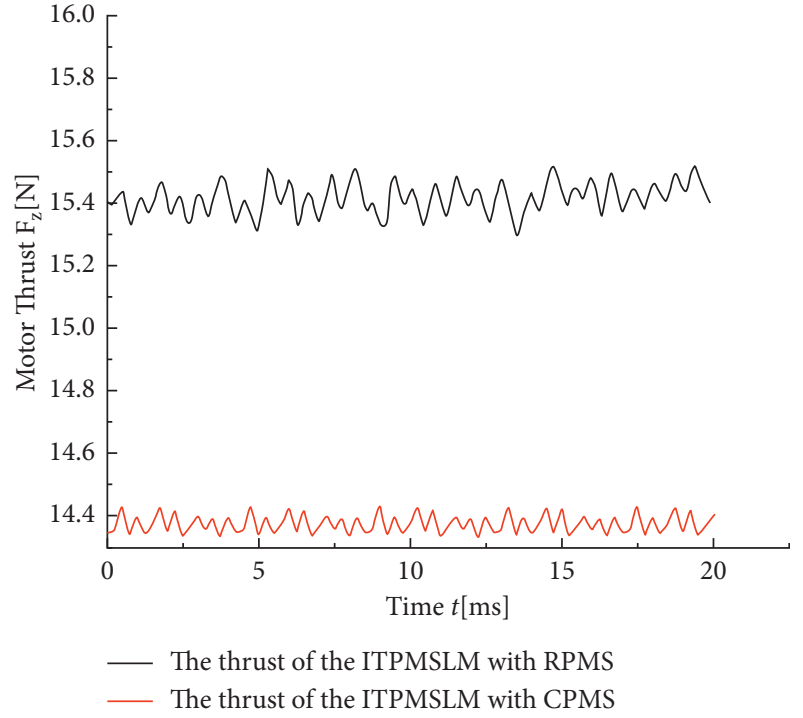

FIgURE 18: Thrust distribution of CPMS and RPMS.

According to the thrust fluctuation test scheme, a new motor is manufactured, and an experimental platform is built. The experimental platform is composed of a feeding device and a detection unit, as shown in Figure 20. The detection unit includes the magnetic grid ruler and reading

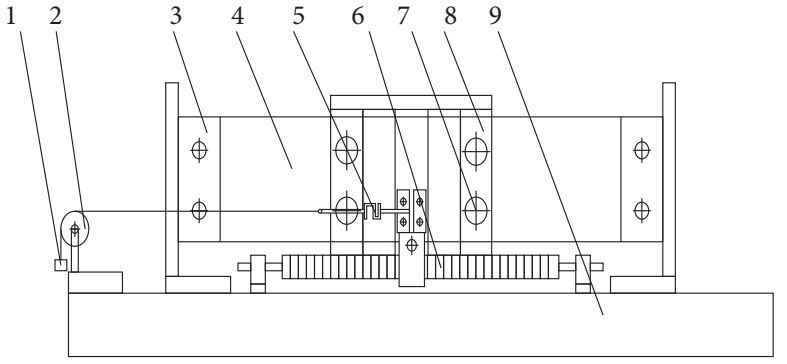

Figure 19: Thrust fluctuation test scheme: (1) load; (2) pulley; (3) support frame; (4) static guide rail; (5) force sensor; (6) new motor.

head, DYLY-102 force measuring sensor and $24 \mathrm{~V}$ DC power supply, DCPCA-090-12-E driver, and driver supporting analysis software and pulley block. Install the force measuring sensor on the auxiliary device, as shown in Figure 21(b). The upper computer controls the driver and adjusts the magnetic grid ruler and the reading head to measure the relative displacement between the mover and the stator. When the motor mover is running, the tooling top force measuring sensor on the workbench measures the motor thrust. To verify the suppression effect of the new motor on thrust fluctuation under different working conditions, the following three groups of experiments are designed: (1) no-load back EMF experimental analysis, (2) 


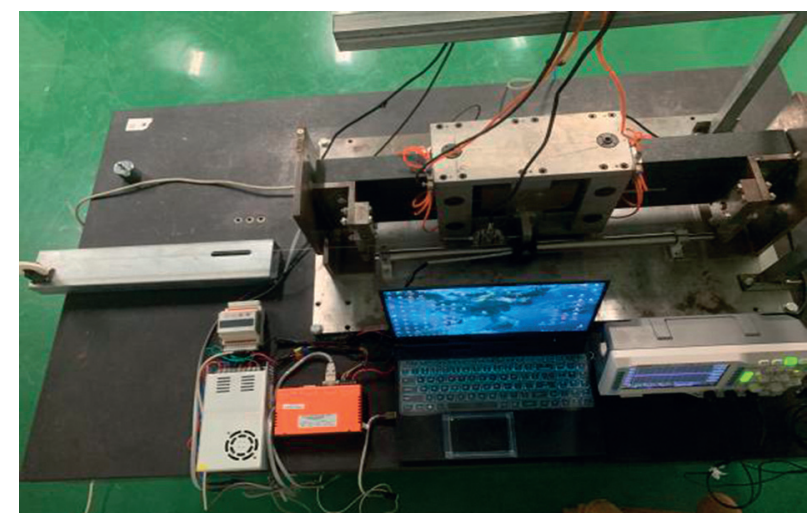

Figure 20: Experimental platform.
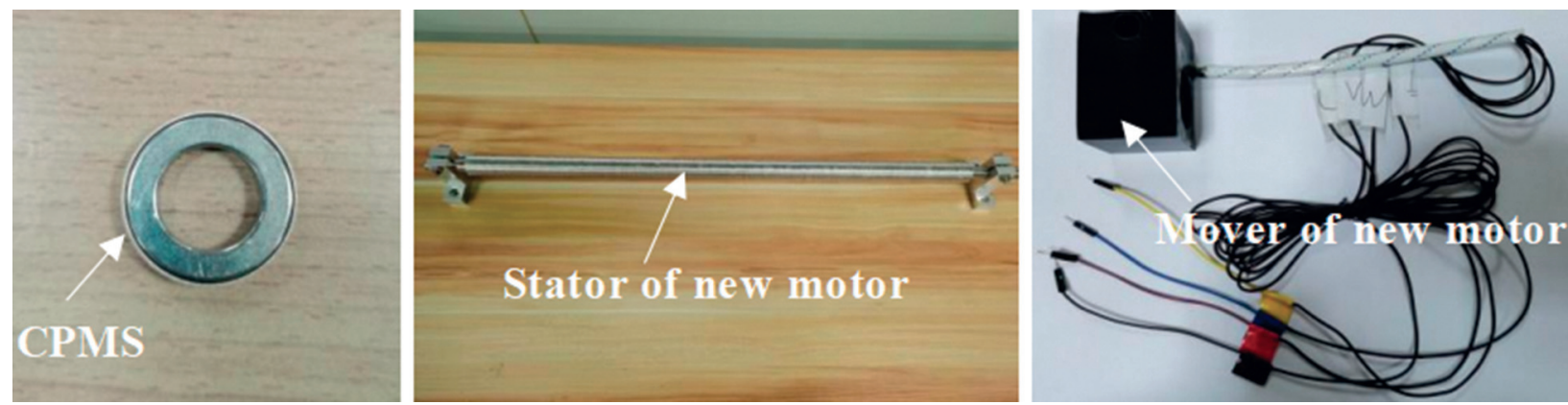

(a)
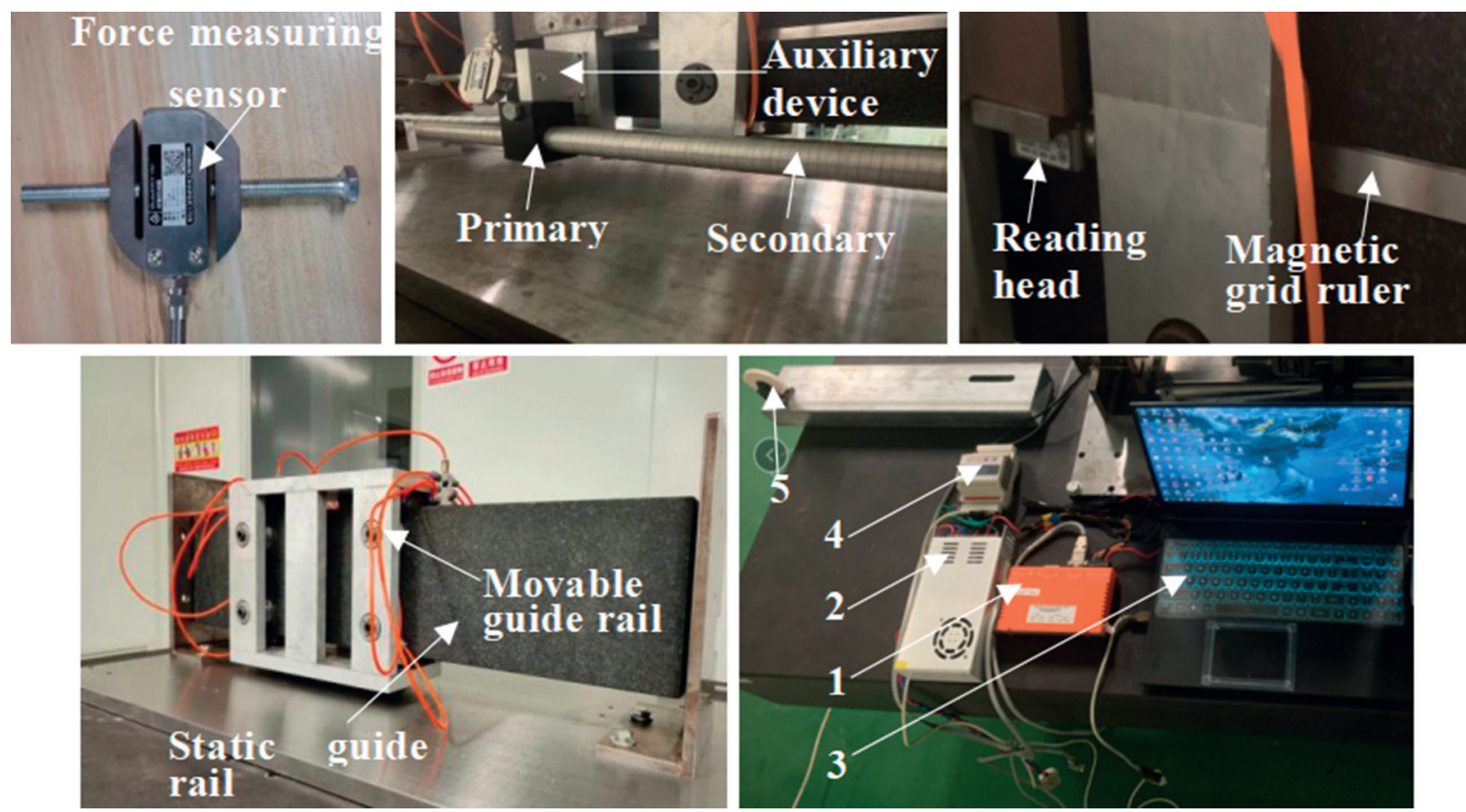

(b)

FIGURE 21: New motor and detection unit: (a) linear motor, primary and secondary; (b) data acquisition and control system ((1) DCPCA090-12-E, (2) 24 V DC, (3) PC, (4) thrust display, and (5) pulley). 


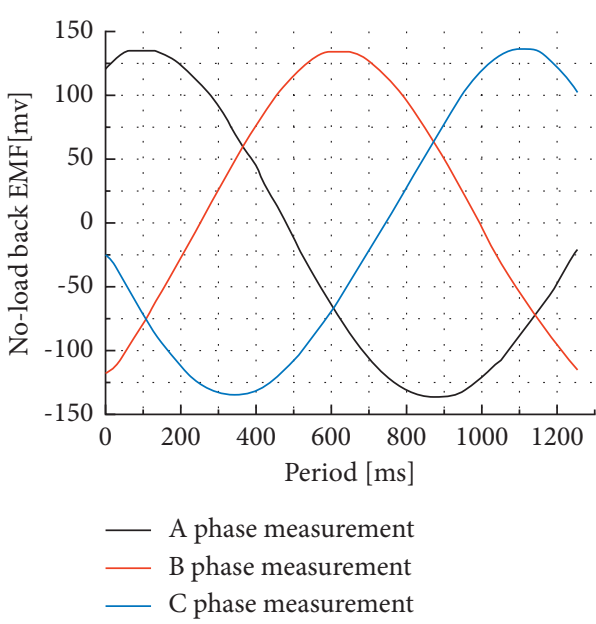

(a)

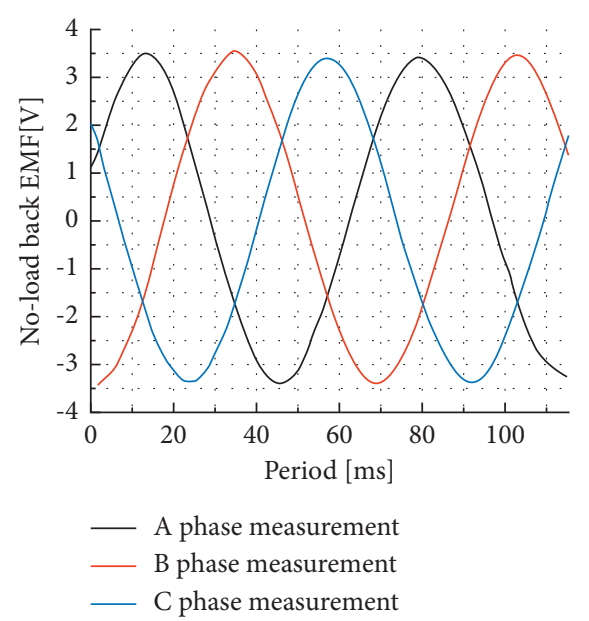

(b)

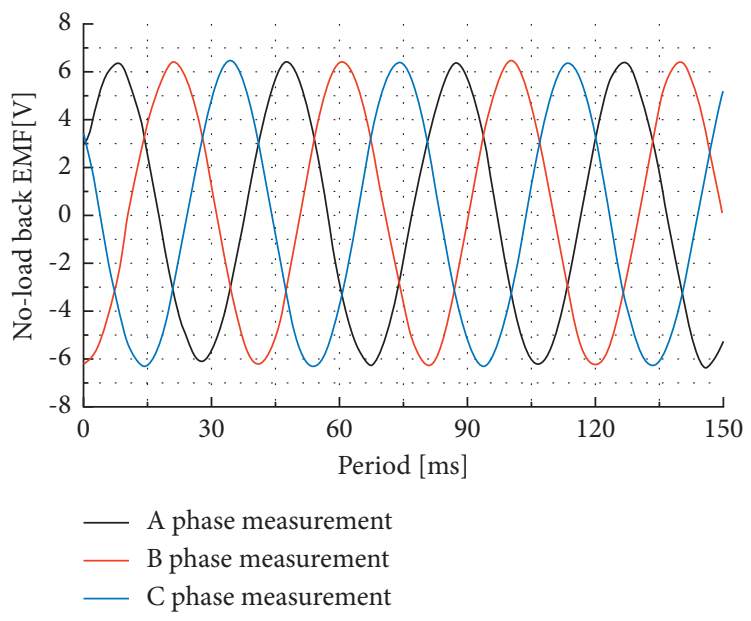

(c)

FIgUre 22: Oscillograph at different speeds: (a) $v=0.02 \mathrm{~m} / \mathrm{s}$; (b) $v=0.6 \mathrm{~m} / \mathrm{s}$; (c) $v=1 \mathrm{~m} / \mathrm{s}$.

load adaptability experimental analysis, and (3) experimental analysis of speed adaptability.

6.2. No-Load Back EMF Test. Three groups of speeds, $v=0.02 \mathrm{~m} / \mathrm{s}, v=0.6 \mathrm{~m} / \mathrm{s}$, and $v=1 \mathrm{~m} / \mathrm{s}$, are tested as shown in Figure 22.

According to the above analysis, the fundamental wave and its higher harmonics are analyzed. When $v$ is $0.02 \mathrm{~m} / \mathrm{s}$, $0.6 \mathrm{~m} / \mathrm{s}$, and $1 \mathrm{~m} / \mathrm{s}$, the no-load back EMF fundamental wave and harmonic of the motor are decomposed to obtain the fundamental wave and harmonic content, respectively, as shown in Figure 23.

Figure 23 shows that there are only a small number of fifth harmonics in the no-load back EMF, and the no-load back EMF waveform distortion is $0.20814 \%, 0.21023 \%$, and $0.21101 \%$. The radial AGMF waveform distribution of the new motor has good sinusoidal property.

6.3. Motor Thrust Test. To verify the load adaptability and speed adaptability of the motor under different working conditions, the following experiments are designed:
(1) Thrust and thrust fluctuation experiments under different loads at the same speed

(2) Thrust and thrust fluctuation experiments at different speeds under the same load

6.3.1. Motor Load Adaptability Test. The thrust and thrust fluctuation experiments under the same speed of $0.08 \mathrm{~m} / \mathrm{s}$ and different loads of $0.1 \mathrm{~kg}, 0.2 \mathrm{~kg}, 0.3 \mathrm{~kg}, 0.4 \mathrm{~kg}$, and $0.5 \mathrm{~kg}$ are built on the experimental test platform to verify the load adaptability of the motor. Fix the dynamometer on the mover and connect it with the weight through the pulley. The measured motor is driven by the control system. The thrust curve is shown in Figure 24.

As shown in Figure 24, the experimental thrust curves of different loads of $0.1 \mathrm{~kg}, 0.2 \mathrm{~kg}, 0.3 \mathrm{~kg}, 0.4 \mathrm{~kg}$, and $0.5 \mathrm{~kg}$ at the speed of $0.08 \mathrm{~m} / \mathrm{s}$ are obtained. The following can be concluded:

(1) In terms of thrust, the average thrust at the same speed $0.08 \mathrm{~m} / \mathrm{s}$ and different loads is $0.98076 \mathrm{~N}$, $1.95886 \mathrm{~N}, 2.94076 \mathrm{~N}, 3.91865 \mathrm{~N}$, and $4.89881 \mathrm{~N}$, and 


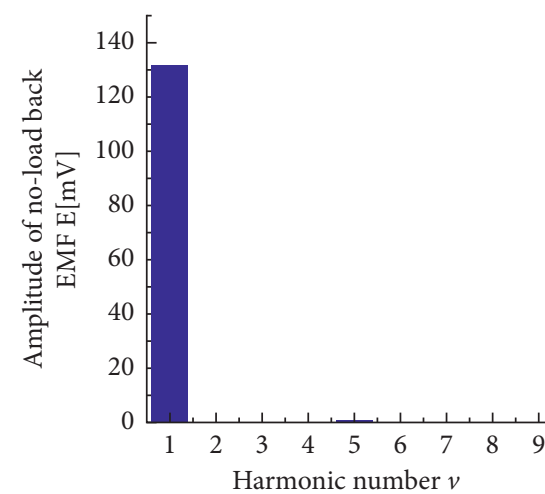

Harmonic distribution

(a)

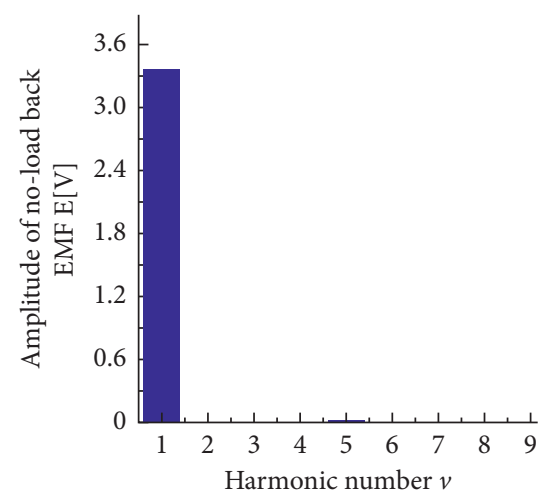

Harmonic distribution

(b)

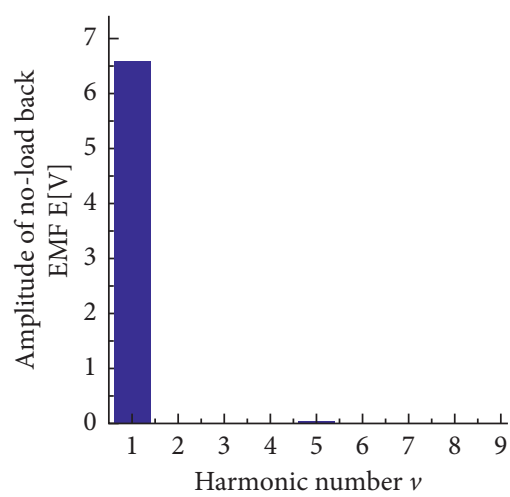

Harmonic distribution

(c)

FIGURE 23: Harmonic analysis diagram of motor back EMF at different speeds: (a) $v=0.02 \mathrm{~m} / \mathrm{s}$; (b) $v=0.6 \mathrm{~m} / \mathrm{s} ;$ (c) $v=1 \mathrm{~m} / \mathrm{s}$.

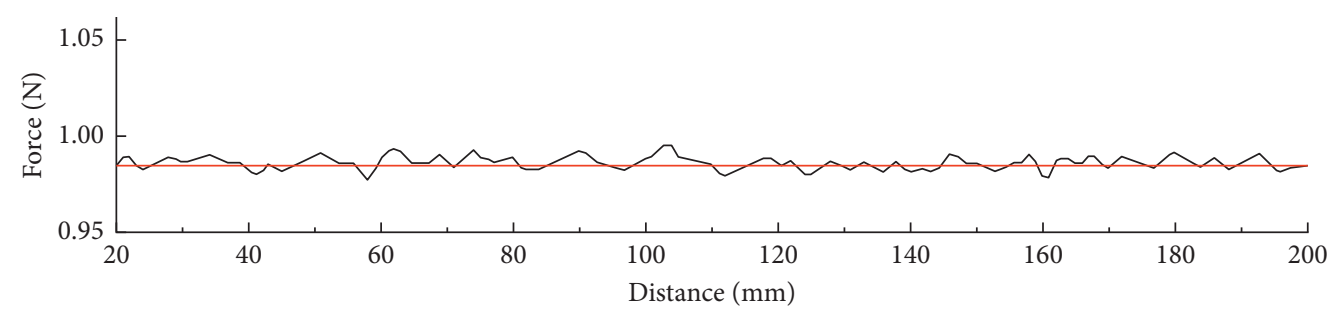

_ Measured value

— Theoretical value

(a)

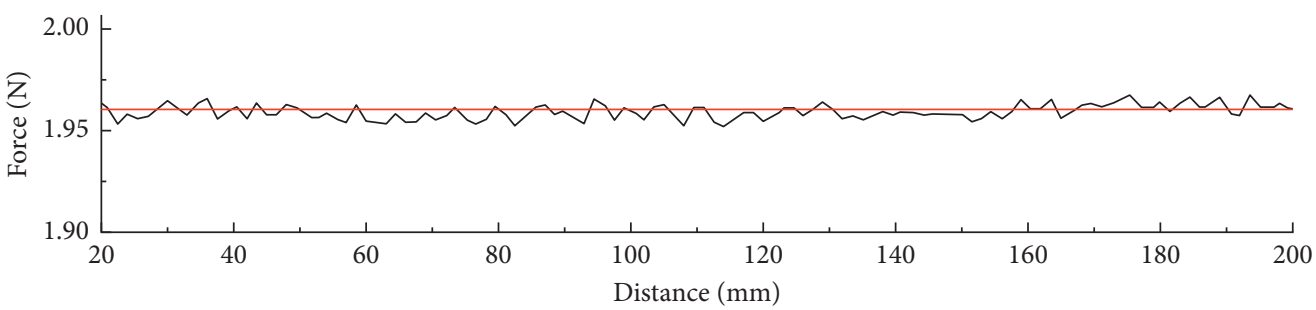

_ Measured value

_ Theoretical value

(b)

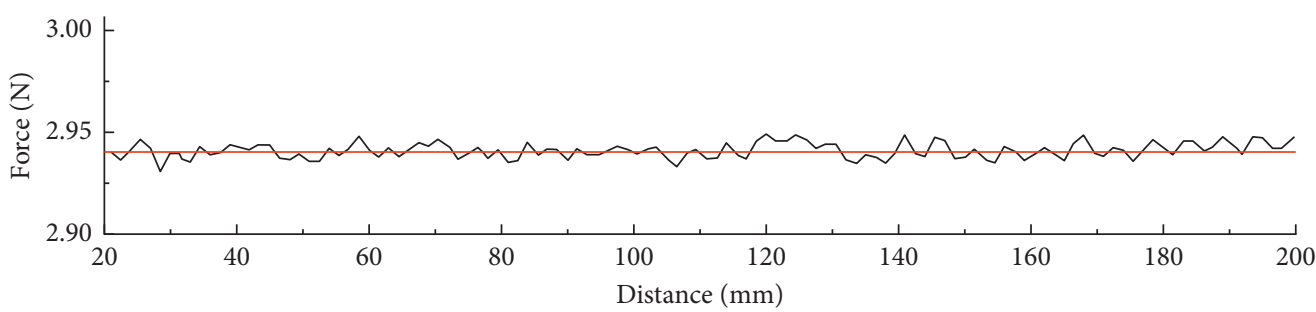

Measured value

Theoretical value

(c)

Figure 24: Continued. 


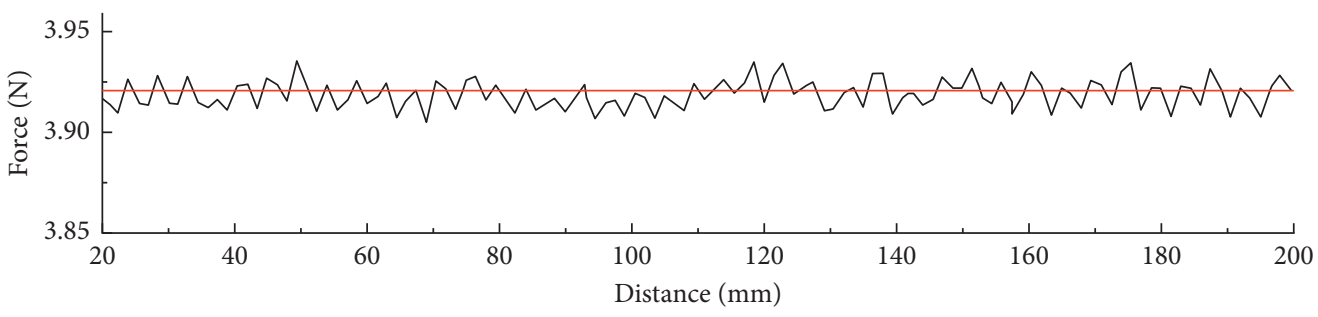

— Measured value

- Theoretical value

(d)

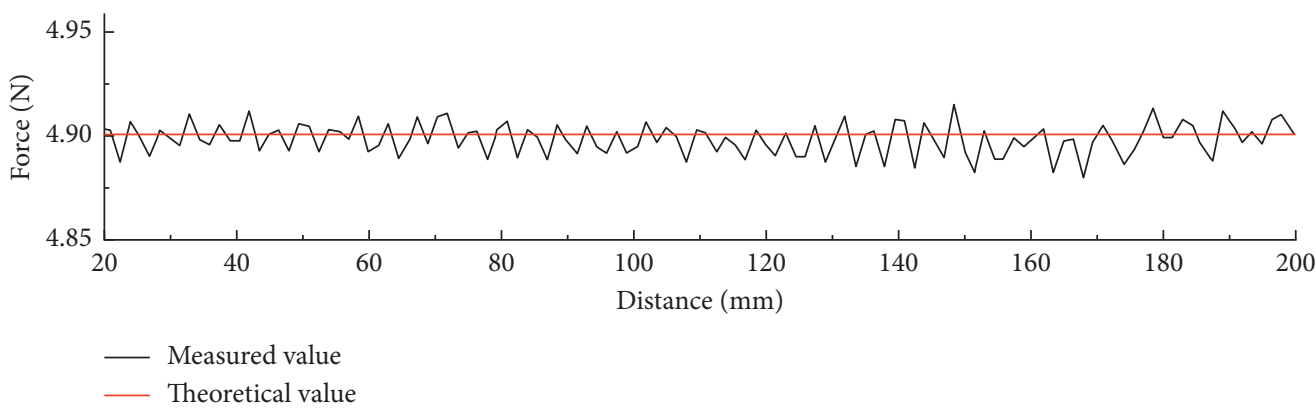

(e)

Figure 24: Thrust comparison diagram of different loads of motor with a speed of $0.08 \mathrm{~m} / \mathrm{s}$ : (a) $0.08 \mathrm{~m} / \mathrm{s}, 0.1 \mathrm{~kg}$; (b) $0.08 \mathrm{~m} / \mathrm{s}, 0.2 \mathrm{~kg}$; (c) $0.08 \mathrm{~m} / \mathrm{s}, 0.3 \mathrm{~kg}$; (d) $0.08 \mathrm{~m} / \mathrm{s}, 0.4 \mathrm{~kg}$; (e) $0.08 \mathrm{~m} / \mathrm{s}, 0.5 \mathrm{~kg}$.

TABLE 5: Thrust fluctuation rate of motor with speed of $0.08 \mathrm{~m} / \mathrm{s}$ under different loads.

\begin{tabular}{lccc}
\hline Load $(\mathrm{g})$ & Measured thrust (\%) & Analytic method (\%) & Error (\%) \\
\hline 100 & 0.00918 & 0.00975 & 5.90 \\
200 & 0.00832 & 0.00930 & 10.57 \\
300 & 0.00827 & 0.00886 & 6.71 \\
400 & 0.00811 & 0.00869 & 6.70 \\
500 & 0.00754 & 0.00808 & 6.69 \\
\hline
\end{tabular}

the corresponding standard values are $0.98015 \mathrm{~N}$, $1.9603 \mathrm{~N}, 2.94045 \mathrm{~N}, 3.9206 \mathrm{~N}$, and $4.90075 \mathrm{~N}$, respectively, with errors of $0.062 \%, 0.073 \%, 0.011 \%$, $0.049 \%$, and $0.039 \%$, which shows that the thrust output of the new motor is relatively stable.

(2) In terms of thrust fluctuation, at the same speed of $0.08 \mathrm{~m} / \mathrm{s}$, when the measured load is $0.1 \mathrm{~kg}, 0.2 \mathrm{~kg}$, $0.3 \mathrm{~kg}, 0.4 \mathrm{~kg}$, and $0.5 \mathrm{~kg}$, the maximum thrust is $0.98536,1.9673,2.94891,3.93596$, and 4.91621 , respectively; the minimum thrust is $0.97636,1.95158$, $2.9302,3.90419$, and 4.87924 , respectively. Table 5 shows that the thrust fluctuation rates are $0.00918 \%$, $0.00832 \%, 0.00827 \%, 0.00811 \%$, and $0.00754 \%$. According to the analytic method, the thrust fluctuation rates are $0.00975 \%, 0.00930 \%, 0.00886 \%$, $0.00869 \%$, and $0.00808 \%$. The errors were $5.9 \%$, $10.57 \%, 6.71 \%, 6.70 \%$, and $6.69 \%$. The errors are within a reasonable range, and the thrust fluctuation $F_{w}$ obtained according to (9) is less than $0.01 \%$. The experiment verified that when the sinusoidal waveform of the AGMF of the new motor is the best, the thrust fluctuation is quite small.
6.3.2. Motor Speed Adaptability Test. We built thrust and thrust fluctuation experiments under the same load of $0.3 \mathrm{~kg}$ and different speeds of $0.05 \mathrm{~m} / \mathrm{s}, 0.06 \mathrm{~m} / \mathrm{s}, 0.07 \mathrm{~m} / \mathrm{s}, 0.08 \mathrm{~m} / \mathrm{s}$, $0.09 \mathrm{~m} / \mathrm{s}$, and $0.1 \mathrm{~m} / \mathrm{s}$ on the experimental platform to verify the speed adaptability of the motor. The obtained thrust curve is shown in Figure 23.

As shown in Figure 25, the conclusions that can be drawn from the analysis charts are as follows:

(1) In terms of thrust, when the same load of $0.3 \mathrm{~kg}$ operates at six speeds, the average thrust is $2.93982 \mathrm{~N}$, $2.94229 \mathrm{~N}, 2.93778 \mathrm{~N}, 2.94076 \mathrm{~N}, 2.93851 \mathrm{~N}$, and $2.94257 \mathrm{~N}$; and the standard value of theoretical thrust is $2.94045 \mathrm{~N}$. The correct values is $0.021 \%$, $0.062 \%, 0.091 \%, 0.011 \%, 0.066 \%$, and $0.072 \%$. This is shown for the same load at different speeds; the thrust output is relatively stable and the increase of thrust fluctuation is small.

(2) In terms of thrust fluctuation, when the same load of $0.3 \mathrm{~kg}$ operates at six speeds, the measured maximum thrust is $2.95221 \mathrm{~N}, 2.95084 \mathrm{~N}, 2.948 \mathrm{~N}$, $2.94891 \mathrm{~N}, 2.95112 \mathrm{~N}$, and $2.95344 \mathrm{~N}$, and the minimum thrust is $2.92814 \mathrm{~N}, \quad 2.92863 \mathrm{~N}$, $2.93019 \mathrm{~N}, 2.9302 \mathrm{~N}, 2.92739 \mathrm{~N}$, and $2.93158 \mathrm{~N}$. Table 6 shows that the thrust fluctuation rates are $0.00818 \%, \quad 0.00755 \%, \quad 0.00601 \%, \quad 0.00827 \%$, $0.00807 \%$, and $0.00743 \%$. Compared with the analytic method, the errors are $6.68 \%, 6.71 \%$, $6.69 \%, 6.71 \%, 6.72 \%$, and $6.68 \%$, and the thrust fluctuation $F_{w}$ obtained according to (9) is less than $0.01 \%$. Therefore, the experiment further verifies that the AGMF composed of CPMS makes 


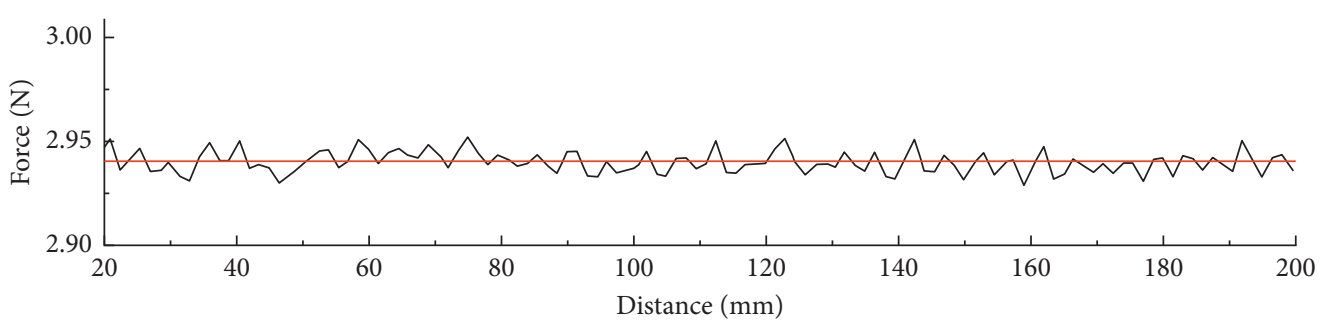

- Measured value

_ Theoretical value

(a)

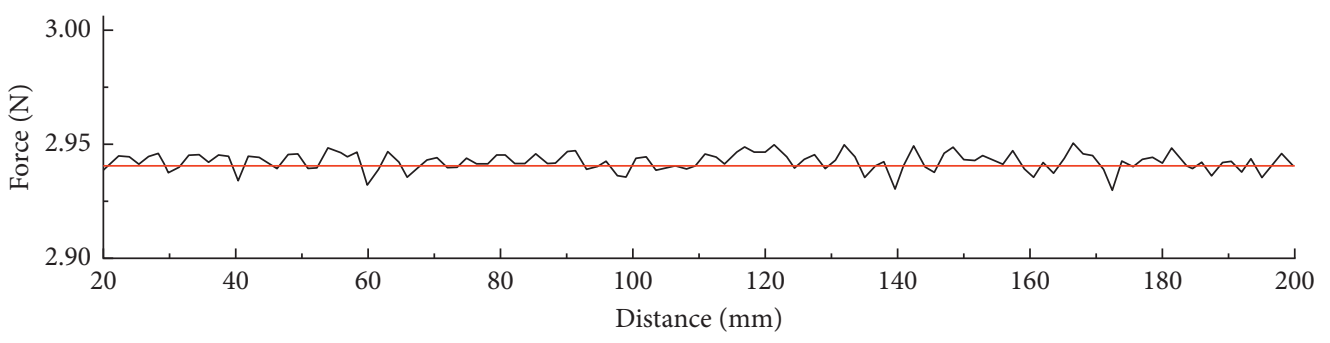

- Measured value

_ Theoretical value

(b)

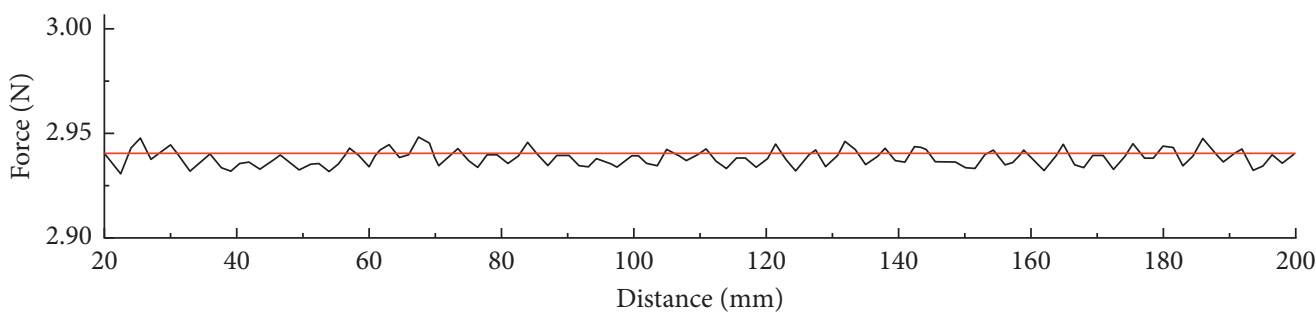

_ Measured value

_ Theoretical value

(c)

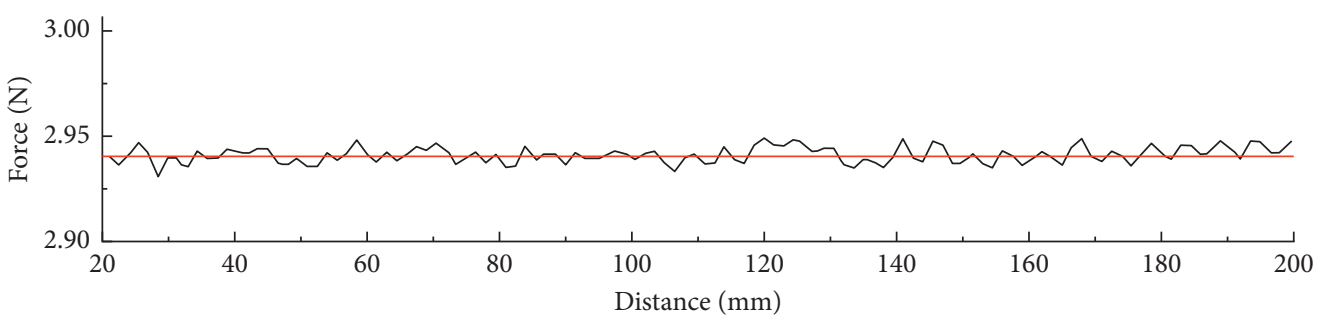

_ Measured value

_ Theoretical value

(d)

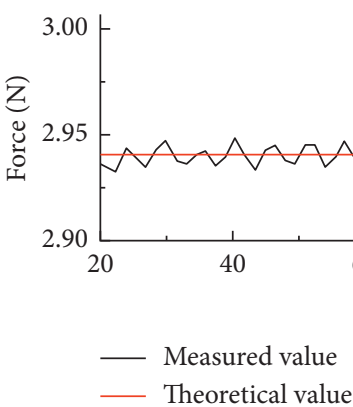

_ Theoretical value 


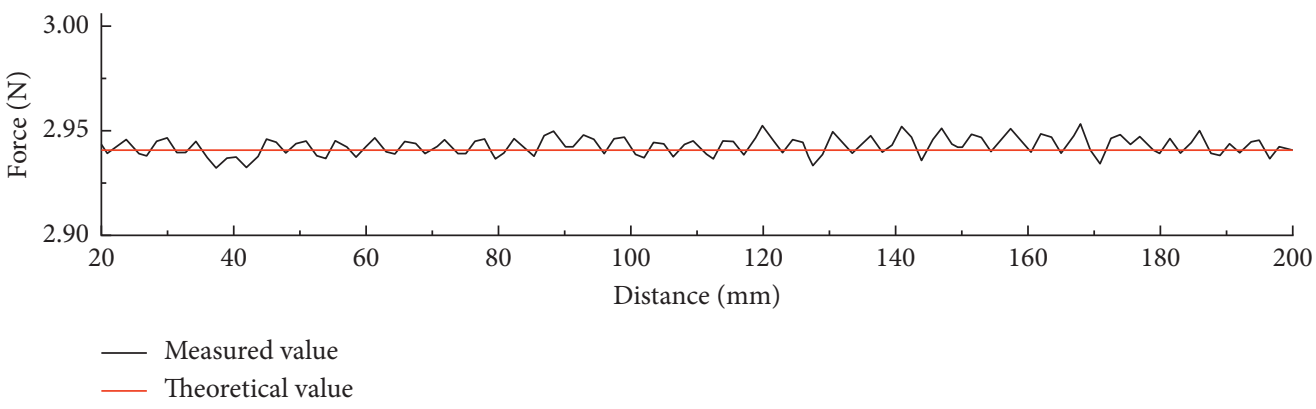

(f)

Figure 25: Comparison of thrust at different motor speeds with a load of $0.3 \mathrm{~kg}$ : (a) $0.3 \mathrm{~kg}, 0.05 \mathrm{~m} / \mathrm{s}$; (b) $0.3 \mathrm{~kg}, 0.06 \mathrm{~m} / \mathrm{s}$; (c) $0.3 \mathrm{~kg}, 0.07 \mathrm{~m} / \mathrm{s}$; (d) $0.3 \mathrm{~kg}, 0.08 \mathrm{~m} / \mathrm{s}$; (e) $0.3 \mathrm{~kg}, 0.09 \mathrm{~m} / \mathrm{s}$; (f) $0.3 \mathrm{~kg}, 0.1 \mathrm{~m} / \mathrm{s}$.

TABLE 6: Thrust fluctuation rate of motor at different speeds when the load is $0.3 \mathrm{~kg}$.

\begin{tabular}{lccc}
\hline Speed $(\mathrm{m} / \mathrm{s})$ & Measured thrust $(\%)$ & Analytic method (\%) & Error $(\%)$ \\
\hline 0.05 & 0.00818 & 0.00876 & 6.68 \\
0.06 & 0.00755 & 0.00809 & 6.71 \\
0.07 & 0.00601 & 0.00644 & 6.69 \\
0.08 & 0.00827 & 0.00886 & 6.71 \\
0.09 & 0.00807 & 0.00865 & 6.72 \\
0.1 & 0.00743 & 0.00796 & 6.68 \\
\hline
\end{tabular}

the thrust fluctuation of the motor relatively stable at different speeds and that the thrust fluctuation rate is significantly reduced. The CPMS has a good effect on restraining the thrust wave of the motor.

\section{Conclusion}

The new motor is designed to reduce thrust fluctuation and improve the driving performance of the motor. The effectiveness of this method is proven by an analytical model build, parameter optimization, and experimental verification. The conclusions are as follows:

(1) In this paper, the analytical calculation model of noload magnetic field of the ITPMSLM by the CPMS is derived by using the magnetic charge method, and the analytical formula of radial AGMF density of the no-load magnetic field is given. On this basis, the analytical formulas of the no-load back EMF and thrust are obtained.

(2) The new motor is analyzed by the analytical method. When the chamfer of a chamfered permanent magnet is $45^{\circ}$ and $h_{1} / h_{2}=0.8$, the waveform distortion rate of radial AGMF is the smallest, and its sinusoidal property is the best. The finite element comparative analysis is carried out between the new motor and the new ITPMSLM with RPMS of the Halbach array. It is verified that compared with the AGMF composed of a conventional permanent magnet, the CPMS can more effectively improve the sinusoidal waveform of radial AGMF so as to suppress the thrust fluctuation.
(3) The experimental prototype is designed and built, and the new motor under different working conditions is tested. The thrust fluctuation rate $F_{w}$ measured in the experiment is less than $0.01 \%$. This verified that the CPMS can effectively improve the sinusoidal waveform of the AGMF of the ITPMSLM and effectively suppress the thrust fluctuation of the new motor. It provides a method to improve the performance of the ITPMSLM.

\section{Data Availability}

The data used to support the findings of this study are included within the article.

\section{Conflicts of Interest}

The authors declare no conflicts of interest.

\section{Acknowledgments}

This research was funded by the National Natural Science Foundation of China (51705390); Natural Science Foundation of Shaanxi Province (2021JM-428); Scientific Research Program Funded by Shaanxi Provincial Education Department (20JK0681); and President Fund of Xi'an Technology and Business College (21YZZ04).

\section{References}

[1] C. Zhang, H. Zhang, P. Ye, and L. Zhang, "Research on sensorless algorithm of two-phase tubular permanent magnet synchronous linear motor," Transactions of China Electrotechnical Society, vol. 34, no. 23, pp. 4901-4908, 2019. 
[2] S. Paul, J. Chang, A. Rajan, and S. Mukhopadhyay, "Design of linear magnetic position sensor used in permanent magnet linear machine with consideration of manufacturing tolerances," IEEE Sensors Journal, vol. 19, no. 13, pp. 5239-5248, 2019.

[3] J. Luo, B. Kou, and X. Yang, "Optimization and design of dual-consequent-pole transverse flux linear machine," Transactions of China Electrotechnical Society, vol. 35, no. 5, pp. 991-1000, 2020.

[4] J. Xia, W. Li, and L. Shen, "Skew and endteeth optimization in reduce permanent magnet linear synchronous motor normal force fluctuation," Advanced Materials Research, vol. 383-390, pp. 4853-4859, 2011.

[5] R. Huang, J. Zhou, and G. T. Kim, "Minimization design of normal force in synchronous permanent magnet planar motor with halbach ray," IEEE Transactions on Magnetics, vol. 44, no. 6, pp. 1526-1529, 2008.

[6] J. Ning, L. Shen, J. Cao, and C. Wang, "Optimization design of permanent magnet linear synchronous motor for reduce normal force fluctuation," Micro Motor, vol. 45, no. 9, pp. 43-47, 2012.

[7] Z. Ling, W. Zhao, and J. Jinghua, "Overviewof high force density permanent magnet linear actuator and its key technology," Transactions of China Electrotechnical Society, vol. 35, no. 5, pp. 1022-1035, 2020.

[8] X. Han, K. Qi, Z. Zhang, and J. Jia, "Analysis and suppression measures of magnetic resistance force in permanent magnet linear synchronous motors," Transactions of China Electrotechnical Society, vol. 30, no. 6, pp. 70-76, 2015.

[9] B. Kou, H. Zhang, S. Guo, and Y. Jin, "Endeffect detent force reduction for permanent magnet linear synchronous motors with auxiliary poles onepiece structure," Transactions of China Electrotechnical Society, vol. 30, no. 6, pp. 106-113, 2015.

[10] J. Xia, L. Shen, B. Peng, and D. Song, "The magnet stagger method to weaken the cogging effect normal force ripple of permanent magnet linear servo motor," Transactions of China Electrotechnical Society, vol. 30, no. 24, pp. 11-16, 2015.

[11] J. Zhang, H. Yu, and Z. Shi, "Research on a tubular linear permanent magnet machines with dual translators for low speed wave energy conversion," Transactions of China Electrotechnical Society, vol. 33, no. 19, pp. 4553-4562, 2018.

[12] K. Zong, J. Zhao, J. Song, Z. He, Y. Yang, and F. Dong, "Thrust ripple reduction based on V-coil permanent magnet synchronous linear motors," Proceedings of the CSEE, vol. 39, no. 22, pp. 6736-6746, 2019.

[13] J. Wang and D. Howe, "Tubular modular permanent mag-net machines equipped with quasi Halbach magnetized mag-nets part II: magnetic field distribution,EMF,and Thrust Force," IEEE Transactions on Magnetics, vol. 41, no. 9, pp. 2479-2489, 2005.

[14] J. Wang and D. Howe, "LIN Zhengyu Design optimization of short stroke single phase tubular permanent magnet motor for refrigeration applications," IEEE Transactions on Industrial Electronics, vol. 57, no. 1, pp. 327-334, 2010.

[15] J. Wang, W. Wang, and A. Kais, “A linear permanent magnet motor for active vehicle suspension," IEEE Transactions on Vehicular Technology, vol. 60, no. 1, pp. 55-63, 2011.

[16] B. Nicola, B. Silverio, and D. C. Dario, "Tubular linear permanent magnet motors:an overall comparison," IEEE Transactions on Industry Applications, vol. 39, no. 2, pp. $466-475,2003$.

[17] B. Nicola, "Analytical field computation of a tubular permanent magnet linear motor," IEEE Transactions on Magnetics, vol. 36, no. 5, pp. 3798-3801, 2000.
[18] J. Zhao, X. Zhang, and J. Zhang, "Field and thrust analysis of tubular permanent magnet linear synchronous motor," Electric Machines and Control, vol. 14, no. 1, pp. 14-17, 2010.

[19] S. M. Jang, J. Y. Choi, S. H. Lee, H. W Cho, and W. B Jang, "Analysis and experimental verification of moving-magnet linear actuator with cylindrical halbach array," IEEE Transactions on Magnetics, vol. 40, no. 4, pp. 2068-2070, 2004.

[20] S. M. Jang and J. Y. Choi, "ThrustAnalysis andMeasurements of tubular linear actuator with cylindrical halbach array," IEEE Transactions on Magnetics, vol. 41, no. 5, 2005.

[21] N Bianchin, S Bolognani, and A. F. Cappello, "Reduction of cogging force in PM linear motors by pole-shifting," IEEE proceedings-electric power applications, vol. 152, no. 3, pp. 703-709, 2005.

[22] J. Cui and C. Qin, "Reduction of cogging force of tubu-lar permanent magnet linear synchronous motors based on permanent magnet shifting," Journal of Shenyang university of technology, vol. 36, no. 2, pp. 133-137, 2014.

[23] J. Dong, Y. Chen, Y. Huang, and Jinlong, “Analytical calculation of no-load magnetic field of cylindrical coreless permanent magnet linear motor," Journal of Southeast University (NATURAL SCIENCE EDITION), vol. 43, no. 5, 2013.

[24] F. Marignetti and M. Searano, "Analysis of PM tubular actuators," in Proceedings of the International conference on electric machines and drives 1999, pp. 440-442, IEEE, Seattle, WA, USA, May 1999.

[25] F. Marignetti and M. Scarano, "Comparative an analysis and design,criteria of permanent magnet tubular actuators," Electrical Engineering, vol. 84, pp. 255-264, 2002.

[26] Z. Q. zhu, P. J. Hor, D. Howe, and J. Rees-Jones, "Novel linear tubular brushless Permanent magnet motor," in Proceedings of the Eighth intemational conference on electrical machines and drives, pp. 91-95, IET, Cambridge, UK, September 1997.

[27] Z. Q. Zhu, P. J. Hor, D. Howe, and J. Rees-jones, "Calculation of cogging force in a novel slotted linear tubula rbrushless Permanent magnet motor," IEEE Transactions on Magnetics, vol. 33, no. 5, pp. 4095-4100, 1997.

[28] P. J. Hor, Z. Q. Zhu, D. Howe, and J. Rees-Jones, "Minimization of cogging force in a linear Permanent magnet motor," IEEE Transactions on Magnetics, vol. 34, no. 5, pp. 3544-3547, 1998.

[29] P. J. Hor, Z. Q. Zhu, and D. Howe, "Eddy current loss in a moving-coil tubular permanent magnet motor," IEEE Transactions on Magnetics, vol. 35, no. 5, pp. 3601-3603, 1999.

[30] Y. Liang, W. Li, and Z. Jiao, "Design and modeling of threephase tubular linear flux- switching permanent magnet motor," in Proceedings of the IEEE Chinese Guidance,Navigation and Control Conference, pp. 2675-2680, IEEE, Yantai,China, August 2014.

[31] Z. Liu, W. Zhao, Ji J. hua, and Q. Chen, “A novel double-stator tubular vernier permanent magnet motor with high thrust density and low cogging force," IEEE Transactions on Magnetics, vol. 51, no. 7, Article ID 8105807, 2015.

[32] J. Xia, X. Li, X. Feng, X. Wang, D. Wang, and Y. Zhang, "Performance analysis of axial flux permanent magnet motor with PCB stator based on new Halbach array," Micro, vol. 11, 2020.

[33] C. Yuan, Y. Han, W. Ma, B. Wang, and S. Luo, "Simulation and performance analysis of permanent magnet electric levitation based on Halbach array," Magnetic materials and Devices, vol. 3, 2021.

[34] D. Guo, Research on Thrust Calculation and Design Method of Cylindrical Linear Motor, Shenyang University of technology, Shenyang, 2008. 